\title{
G-quadruplexes as versatile scaffolds for catalysis
}

$\operatorname{AUTHOR}(S)$ :

Yum, Ji Hye; Park, Soyoung; Sugiyama, Hiroshi

CITATION:

Yum, Ji Hye ...[et al]. G-quadruplexes as versatile scaffolds for catalysis.

Organic \& biomolecular chemistry 2019, 17(44): 9547-9561

ISSUE DATE:

2019-11-28

URL:

http://hdl.handle.net/2433/245364

\section{RIGHT:}

This is the accepted manuscript of the article, which has been published in final form at

https://doi.org/10.1039/C9OB01876J; The full-text file will be made open to the public on 17 October 2020 in

accordance with publisher's 'Terms and Conditions for Self-Archiving'; この論文は出版社版でありません。引用の際に

は出版社版をご確認ざ利用ください。; This is not the published version. Please cite only the published version. 


\title{
G-quadruplex as a Versatile Scaffold for Catalysis
}

\author{
Ji Hye Yum, ${ }^{1}$ Soyoung Park, ${ }^{*}{ }^{1}$ and Hiroshi Sugiyama ${ }^{*},{ }^{2}$ \\ 'Department of Chemistry, Graduate School of Science, Kyoto University, \\ Kitashirakawa-oiwakecho, Sakyo-ku, Kyoto 606-8502, Japan \\ ${ }^{2}$ Institute for Integrated Cell-Material Sciences (iCeMS), Kyoto University, \\ Yoshida-ushinomiyacho, Sakyo-ku, Kyoto 606-8501, Japan
}

*Corresponding author: Dr. Soyoung Park, Prof. Dr. Hiroshi Sugiyama

Tel.: (+)81-75-753-4002; Fax: (+)81-75-753-3670

E-mail: oleesy@kuchem.kyoto-u.ac.jp,hs@kuchem.kyoto-u.ac.jp (H.S.)

Received Date: (to be automatically inserted after your manuscript is accepted if required according to the journal that you are submitting your paper to)

\section{KEYWORDS}

G-quadruplex DNA, Asymmetric synthesis, DNA hybrid catalyst, Metalloenzymes 


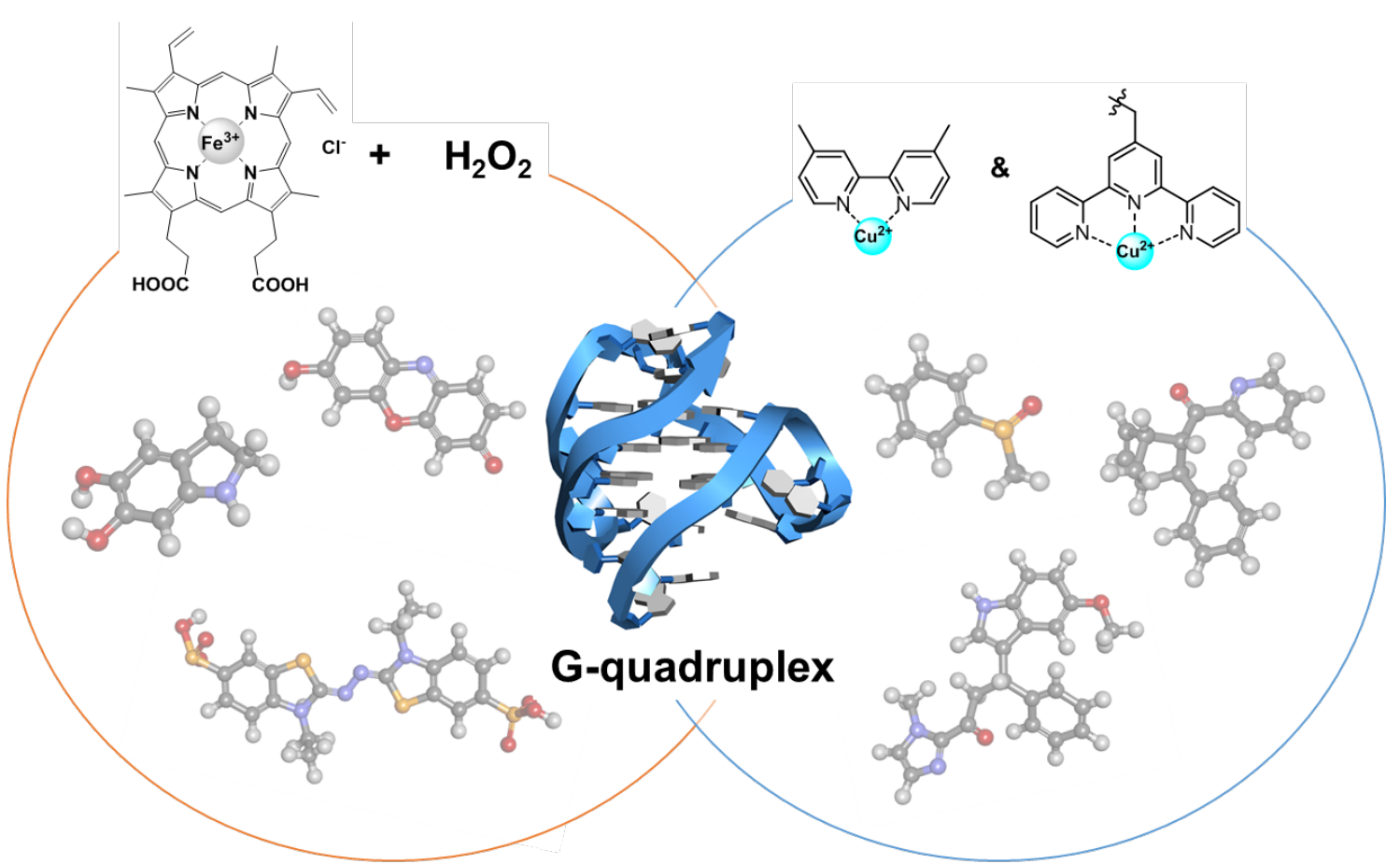

Oxidative catalysis

Asymmetric catalysis

\begin{abstract}
DNA is receiving attention as a useful biomaterial in a broad range of research fields beyond its classical role as a biopolymer for storage and delivery of genetic information. Based on its chemical and thermal stability and easy accessibility, a series of DNA-based hybrid catalysts has been developed and successfully applied to various asymmetric reactions in water. Besides the canonical Watson-Crick duplex, the G-quadruplex structure has been actively exploited as horseradish-peroxidase (HRP)-mimicking DNAzymes via specific complexation with hemin. G-Quadruplex also provides a fascinating scaffold to develop a switchable catalytic system. This review summarizes the beginning, progress, and perspective of the noncanonical DNA-based hybrid catalysts, focusing on the G-quadruplex as a versatile scaffold for catalysis.
\end{abstract}

\title{
Introduction
}

For modern scientists, DNA is no longer just a rigid biopolymer for storage and delivery of genetic information in living organisms. As a result of the rapid advance of molecular biology, chemical biology, and synthetic biology, we can now readily interpret whole-genome sequences of various living organisms and many of the secrets of DNA sequences that control biological phenomena such as development, diseases, and senescence have been unveiled.' DNA is not only an object of biological study, it also plays an important role as a superb biomaterial for the 
construction of nanostructures. Thanks to the precise and controllable complementarity of DNA, DNA nanotechnology has enjoyed a golden age from the production of simple nanoblocks to fabrication of sophisticated nanomachines.2

Catalysis is one promising research area in which DNA is exploited for chemical applications. However, in general, the role of DNA in catalysis has remained in the shadow of catalytic RNAs (ribozymes), and it has received little attention compared with RNA; indeed, unlike natural ribozymes, DNAzymes have not yet been found in nature, and DNAzymes can only be evolved through in vitro selection. ${ }^{3}$ Recently, DNA has been receiving attention as a unique chiral source in the field of asymmetric catalysis. DNA-induced rate acceleration was also observed in DNA-based asymmetric catalysis. ${ }^{4}$ Given that DNA is chemically stable and easy to handle, it constitutes a suitable biopolymer to develop water-compatible catalysts. Another important benefit of DNA is its conformational flexibility; indeed, DNA is a dynamic biomolecule that can be readily controlled. Besides the predominant canonical Watson-Crick duplex (right-handed B-form DNA), a variety of noncanonical secondary structures such as left-handed Z-DNA, triplex, i-motif, and quadruplexes have been found under specific conditions (Figure 1).

In particular, the G-quadruplex structure has gained remarkable attention because of its structural diversity, which is derived from combinations of parallel and antiparallel strands, different loop sequences, and shapes. ${ }^{6}$ It is noteworthy that plastic conformations of G-quadruplexes can be used as a stimuli-responsive switch. For example, this structural feature of the G-quadruplex has been actively exploited as a chiral scaffold to develop changeable chiral catalysts. This review addresses the application of the noncanonical DNA structures, focusing on G-quadruplexes as a useful and versatile scaffold for catalysis. Several synonyms have been used for G-quadruplex DNAzymes and G-quadruplex-based hybrid catalysts such as G-quadruplex hybrid catalysts and G-quadruplex DNA metalloenzymes, and these terms are also used in this review. For canonical double-helix DNA, its application for catalysis is described comprehensively in other articles and is not covered this review. ${ }^{\text {thete }}$ 
A)

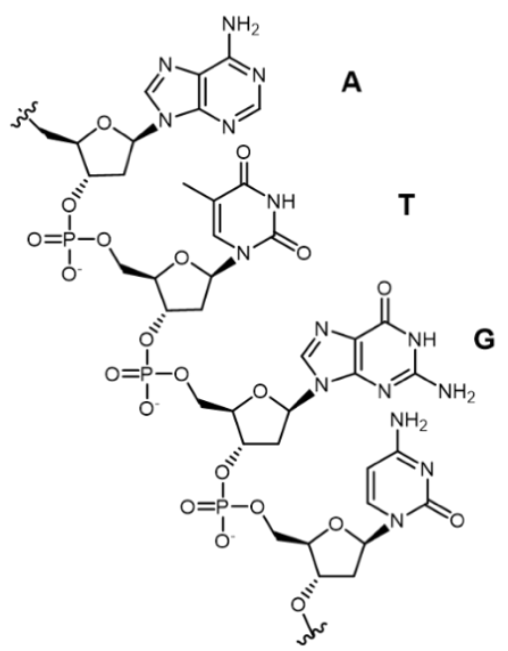

B)

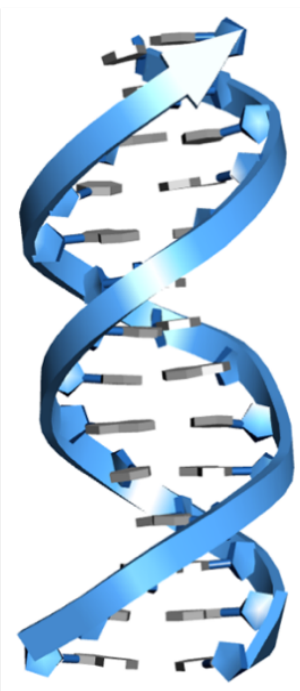

C)

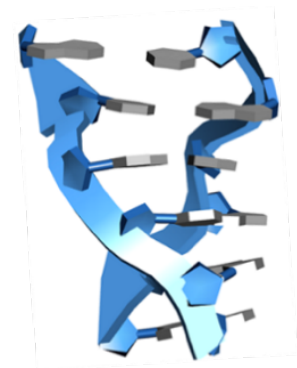

D)

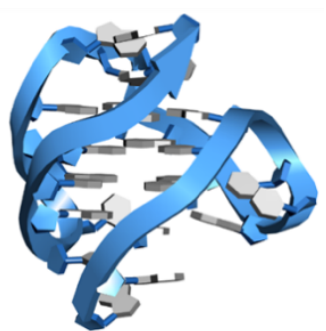

Figure 1. The chemical structure of DNA and various DNA secondary structures

A) The chemical structures of the four nucleotides. B) Helical chirality of the canonical B-form duplex [5'-d(GCGCATGCTACGCG)-3' and its complement strands, PDB ID: 2M2C]. C) Representative noncanonical Z-form DNA [ $5^{\prime}-\mathrm{d}(\mathrm{CGC} * \mathbf{G C G})-3^{\prime}$ here ${ }^{*} \mathrm{G}$ is 8-methylguanosine, PDB ID: 1TNE]. D) Representative noncanonical G-quadruplex DNA [5'-d( A $\left._{3}\left(\mathrm{G}_{3} \mathrm{TTA}\right)_{3}-\mathrm{G}_{3} \mathrm{AA}\right)-3^{\prime}$, PDB ID: 2HY9].

\section{G-quadruplex DNA}

A)

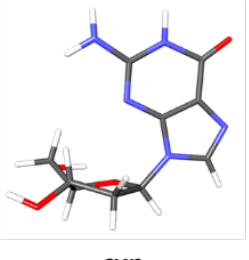

syn

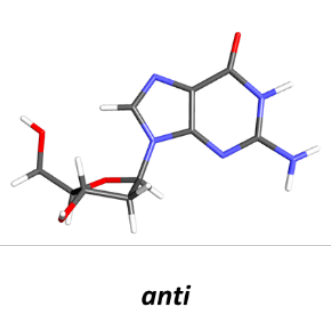

B)

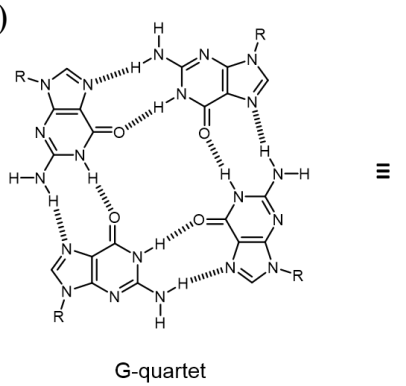

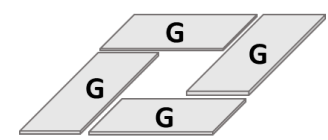

Figure 2. Guanine quartet plane composed of the four guanine residues

A) Two guanine glycosidic angle conformations, syn and anti, for the varied formation of G-quadruplex. B) The arrangement of the four guanine bases in a G-quartet plane; the G-quartet is illustrated as a gray square in this review. 


\begin{tabular}{cc}
\hline Name & \multicolumn{1}{c}{ Sequence } \\
\hline HT-21 & 5'-GGGTTAGGGTTAGGGTTAGGG-3' \\
c-kit & 5'-AGGGAGGGCGCTGGGAGGAGGG-3' \\
c-myc & 5'-TGAGGGTGGTGAGGGTGGGGAAGG-3' \\
HT-45 & 5'-(GGGTTA) ${ }_{3}$ GGG-TTA-(GGGTTA) ${ }_{3}$ GGG-3' \\
HT-69 & 5'-(GGGTTA) ${ }_{3}$ GGG-TTA-(GGGTTA) -TTA-(GGGTTA) $_{3}$ GGG-3'
\end{tabular}

Table 1. G-quadruplex-forming oligonucleotide sequences addressed in this review

Guanine residues can assemble into planar molecular squares called G-quartets or G-tetrads. As shown in Figure 2, four guanine nucleosides within a tetrad exist in either anti- or syn conformation and interact through hydrogen bonding between the Watson-Crick and Hoogsteen faces of the guanine bases. The formation of guanine-rich DNA sequences affords tetra-stranded helices now known as G-quadruplexes, which are further stabilized by electrostatic interactions in the presence of monovalent cations such as $\mathrm{Na}^{+}, \mathrm{K}^{+}$, and $\mathrm{NH}_{4}{ }^{+} \cdot{ }^{\mathrm{s}}$ Representative G-quadruplex-forming oligonucleotide sequences are shown in Table 1.

To date, several G-rich sequences that form G-quadruplexes have been identified, and their conformations have been extensively studied through various analytical techniques such as X-ray crystallography, NMR spectroscopy, and circular dichroism (CD) spectroscopy. In particular, CD spectroscopy is the most convenient and widely used tool for the characterization of G-quadruplex structures. G-Quadruplex can display a variety of topologies, depending on several factors such as DNA sequence, DNA strand direction, and monovalent cations. Particular G-quadruplex conformations can be determined using CD spectroscopy. For example, CD spectra of molecules with a parallel G-quadruplex conformation feature a negative signal around $240 \mathrm{~nm}$ and a positive signal around $262 \mathrm{~nm}$. Molecules adopting an antiparallel conformation present a negative signal around $260 \mathrm{~nm}$ and a positive signal around $300 \mathrm{~nm} .{ }^{10} \mathrm{In}$ the case of hybrid G-quadruplex structures, a negative signal around $240 \mathrm{~nm}$ and positive signals around 262 and $300 \mathrm{~nm}$ are observed. Higher-order G-quadruplex structures can also be characterized by their unique CD spectral signatures, as shown in Figure 3. ${ }^{11}$ CD spectroscopic analysis is thus generally used to investigate the structural and mechanistic aspects of G-quadruplex DNA-based asymmetric catalysis, such as the relationship between G-quadruplex topologies and enantioselectivity, and the structural transition of G-quadruplex by metal-binding ligand complexes. 


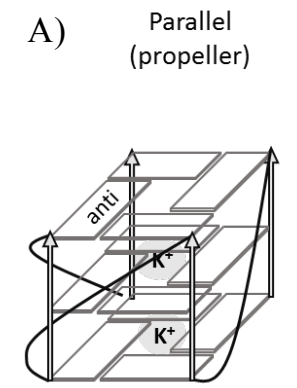

B)

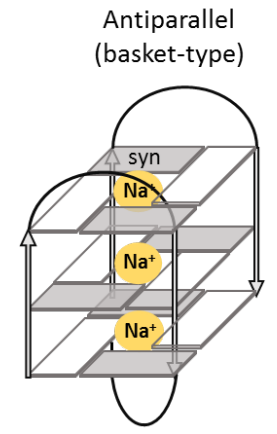

Mixed or Hybrid-1

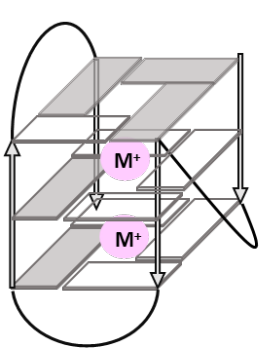

Higher-order structure

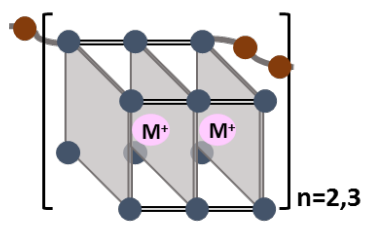

\begin{tabular}{|c|c|c|c|c|}
\hline wavelength & Parallel $\mathbf{G}_{\mathbf{4}}$ & Antiparallel $\mathbf{G}_{\mathbf{4}}$ & ${\text { Hybrid } \mathbf{G}_{\mathbf{4}}}$ & Higher-order $\mathbf{G}_{\mathbf{4}}$ \\
\hline Positive peaks & ca $262 \mathrm{~nm}$ & ca $300 \mathrm{~nm}$ & ca $262 \mathrm{~nm}$ and $300 \mathrm{~nm}$ & $\begin{array}{c}\text { ca } 300 \mathrm{~nm}, 270 \mathrm{~nm} \\
\text { and } 250 \mathrm{~nm}\end{array}$ \\
\hline Negative peaks & ca $240 \mathrm{~nm}$ & ca $260 \mathrm{~nm}$ & ca $240 \mathrm{~nm}$ & ca $240 \mathrm{~nm}$ \\
\hline
\end{tabular}

Figure 3. Possible configurations of human telomeric G-quadruplex DNA

A) Possible configurations of human telomeric G-quadruplex DNA $\left(\mathrm{M}^{+}\right.$is a monovalent ion for structure stabilization; $\mathrm{M}^{+}=\mathrm{NH}_{4}^{+}$or $\mathrm{K}^{+}$). B) The characteristic wavelength of positive and negative peaks on the CD spectra of HT21 G-quadruplex.

\section{Hemin/G-quadruplex DNAzyme for oxidation reactions}

Iron porphyrins occur abundantly as coordination complexes in nature and they act as cofactors and prosthetic groups in many enzymes that are responsible for electron-transfer reactions, oxygen-transfer reactions, and photosynthesis. ${ }^{12}$ Recently, the remarkable ability of heme proteins such as cytochrome P450 and myoglobin is gaining the spotlight in carbenoid chemistry. ${ }^{13}$ The use of hemin (a protoporphyrin IX complex of an iron(III) ion) itself has also been investigated in organic synthesis. ${ }^{14}$ Interestingly, hemin can interact with G-quadruplex structures and this complexation endows the hemin/G-quadruplex system with noteworthy catalytic properties in oxidation reactions. In 1998, Sen and coworkers reported that single-stranded guanine-rich DNA sequences formed specific hemin-binding structures through intramolecular G-quadruplex formation, and the DNA-hemin complexes had higher peroxidase activity than that of hemin alone. ${ }^{15}$ Since then, the unique activity of hemin/G-quadruplex has been actively exploited through the concepts of "horseradish-peroxidase (HRP)-mimicking DNAzymes," "G-quadruplex(G4)/hemin DNAzymes," or "heme·DNAzymes." 

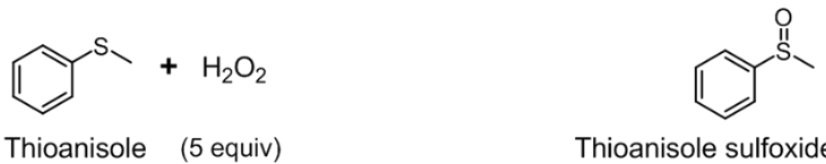

Thioanisole (5 equiv)

Thioanisole sulfoxides (TSO)

up to $85 \%$ conv. (no ee)

$\mathrm{V}_{0}=3500[\mathrm{nM} / \mathrm{s}]$

$k_{\text {cat }}=3.5[/ \mathrm{s}]$

\section{G4 DNA RNA/Hemin}
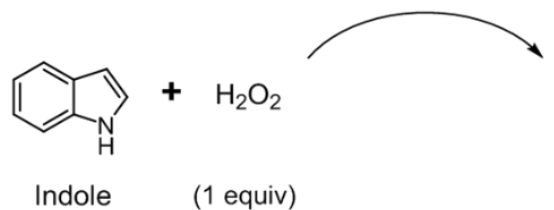

Indole

(1 equiv)
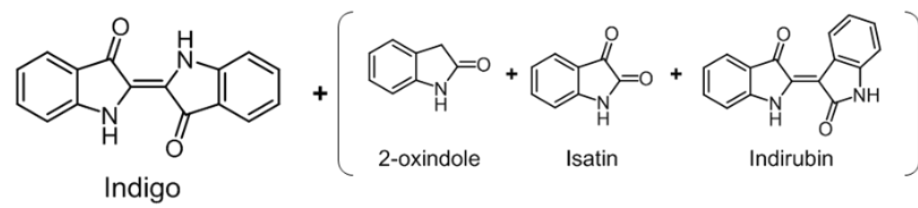

Figure 4. The oxidation of thioanisole and indole catalyzed by G4/Hemin complexes (Poon, JACS, 2011). Copyright ACS

Sen and coworkers verified peroxidase activity of G-quadruplex/heme complexes (named nucleoheme) in oxygen-transfer reactions from hydrogen peroxide to representative substrates such as thioanisole and indoles. ${ }^{16}$ G-quadruplex DNA (RNA)/heme complex could be activated in $\mathrm{H}_{2} \mathrm{O}_{2}$ solution and the oxygen-transfer product, thioanisole sulfoxide (TSO), was formed from thioanisole with up to ca $85 \%$ conversion with no enantioselectivity (Figure 4). Moreover, the calculated turnover rate $\left(k_{\mathrm{cat}}\right)$ of $3.5[/ \mathrm{s}]$ suggests that the efficiency of their DNAzyme can be comparable to those of some peroxidases. For indole, the oxygen-transfer reaction by G-quadruplex DNA (RNA)/heme complex gave a number of different oxidized products including isatin, 2-oxindole, and indirubin as well as blue dye indigo. Their studies suggested that readily synthesizable and thermally stable nucleic acids provide binding sites for hemin and that this complex could function as an oxygen-transfer catalyst like proteinaceous heme enzymes.

Oxidation of $\mathrm{NADH}$

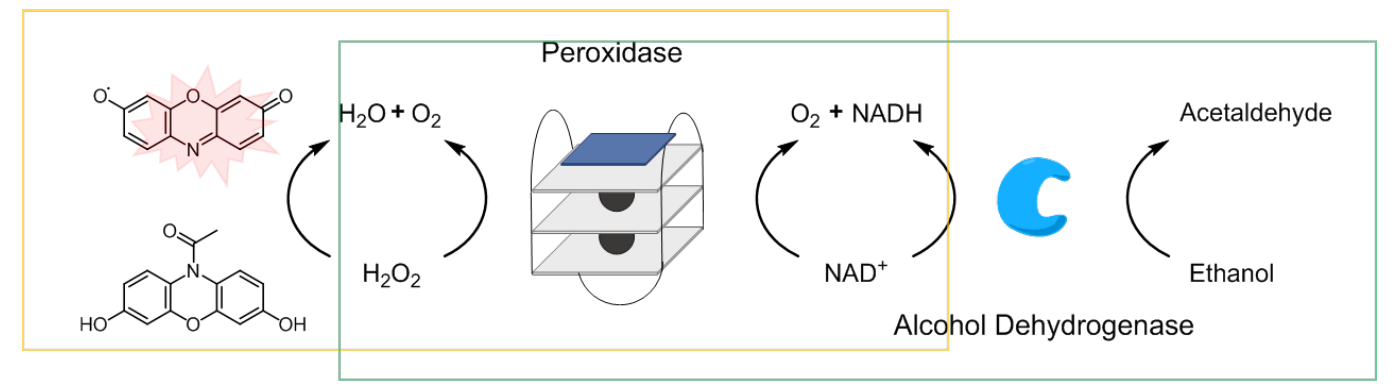

Regeneration of $\mathrm{NADH}$ 
Figure 5. NADH-peroxidase-mimicking activity of G4/Hemin catalyst in the cascade catalytic cycle (Golub, ACIE, 2011). Copyright WILEY-VCH

Around the same time as the seminal work of the Sen group, Willner and coworkers reported that hemin/G-quadruplex could function as a nicotinamide-adenine-dinucleotide (NADH)-oxidase- and NADH-peroxidase-mimicking biocatalyst. ${ }^{17}$ They devised an oxidation reaction system that consisted of a hemin/G-quadruplex, NADH, and Amplex Red. Hemin/G-quadruplex DNAzyme catalyzed the oxidation of NADH by molecular oxygen to give $\mathrm{NAD}^{+}$with the formation of $\mathrm{H}_{2} \mathrm{O}_{2}$, and subsequent oxidation of Amplex Red by $\mathrm{H}_{2} \mathrm{O}_{2}$ occurred, affording highly fluorescent resorufin. The potential of hemin/G-quadruplex as an oxidation catalyst was also demonstrated by the combination of $\mathrm{NAD}^{+}$-dependent enzyme-catalyzed reaction to generate NADH cofactor. Under aerobic conditions, hemin/G-quadruplex DNAzyme catalyzed the oxidation of NADH to NAD ${ }^{+}$with the formation of $\mathrm{H}_{2} \mathrm{O}_{2}$, and NADH could be regenerated by alcohol dehydrogenase $(\mathrm{AlcDH})$-catalyzed oxidation of ethanol. This system was successfully validated by monitoring the fluorescence of resorufin generated by DNAzyme-catalyzed oxidation. Furthermore, the authors found that hemin/G-quadruplex catalyzes the oxidation of NADH by $\mathrm{H}_{2} \mathrm{O}_{2}$ under anaerobic conditions. This result indicates that hemin/G-quadruplex DNAzymes can act as an NADH peroxidase as well as NADH oxidase, albeit with low efficiency $\left(k_{\mathrm{cat}} \sim 4.6\left[10^{-3} / \mathrm{s}\right]\right)$ compared with the catalytic activity of the NADH (per)oxidase $\left(k_{\text {cat }} \sim 5.1[/ \mathrm{s}]\right)$.

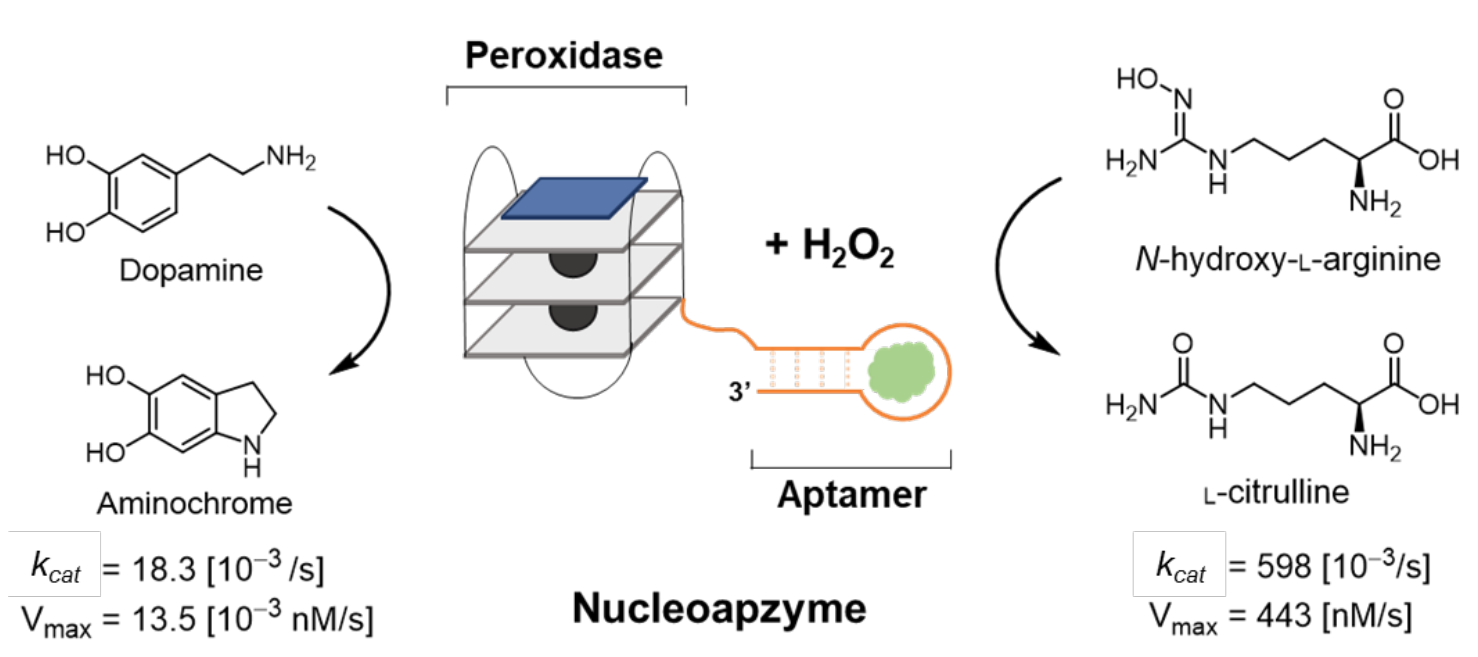

Figure 6. The oxidation of dopamine and $N$-hydroxy-L-arginine catalyzed by $\mathrm{G} 4 /$ hemin-based nucleoapzyme (Golub, JACS, 2016). Copyright ACS

Despite these notable findings on DNAzymes, the low binding affinity for a range of substrates has been considered to be the main reason for the inferior catalytic activities of 
DNAzymes compared with native enzymes, which $\boldsymbol{k}_{\text {cat }} / \boldsymbol{K}_{\boldsymbol{m}}$ value for the oxidation reaction is up to $10^{7} \mathrm{M} / \mathrm{s} .{ }^{18}$ Willner and coworkers introduced a new strategy to enhance the catalytic performance of DNAzymes. ${ }^{19}$ They focused on the ligand-binding DNA sequences (aptamers) and devised a substrate-binding-site hybrid DNAzyme, named "nucleoapzyme." Two different nucleoapzymes were developed through the incorporation of dopamine- or $N$-hydroxy-L-arginine-binding aptamer sequences into hemin/G-quadruplex DNAzymes and these were used to investigate the oxidation of dopamine to aminochrome and the oxidation of $N$-hydroxy-L-arginine to L-citrulline in the presence of $\mathrm{H}_{2} \mathrm{O}_{2}$. The designed nucleoapzymes clearly showed enhanced catalytic performance compared with hemin/G-quadruplex alone. In their follow-up studies, Willner and coworkers designed a series of supramolecular hemin/G-quadruplex-dopamine aptamer nucleoapzymes by duplex and duplex/triplex hybridization and investigated systematically the effect on catalytic activities of spatial proximity of hemin/G-quadruplex as a catalytic site and dopamine-binding aptamer as a substrate-binding site. ${ }^{19 \mathrm{c}}$ Interestingly, the potential of switchable catalysis was demonstrated based on the programmable DNA hybridization between nucleoapzyme and toehold strand. Micelle-based nucleoapzyme was also developed by supramolecular assembly of lipidated G-quadruplex and a lipidated dopamine-binding aptamer sequence. Very recently, the concept of nucleoapzyme has expanded to include transition-metal ion complex/aptamer nucleoapzymes beyond hemin/G-quadruplex complexes. ${ }^{19 \mathrm{~d}} \mathrm{Cu}$ (II)- and Fe(III)-terpyridine nucleoapzymes were developed for the $\mathrm{H}_{2} \mathrm{O}_{2}$-assisted oxidation of dopamine to aminochrome and afforded 60 -fold and 140-fold catalytic enhancements, respectively, compared with separated metal-terpyridine complex and the dopamine-binding aptamer. Their strategy compensates the limitation of typical DNAzymes through the hybridization of the aptameric region as a substrate-binding site. The approach is expected to expand the application of bioinspired catalysts for various chemical transformations.

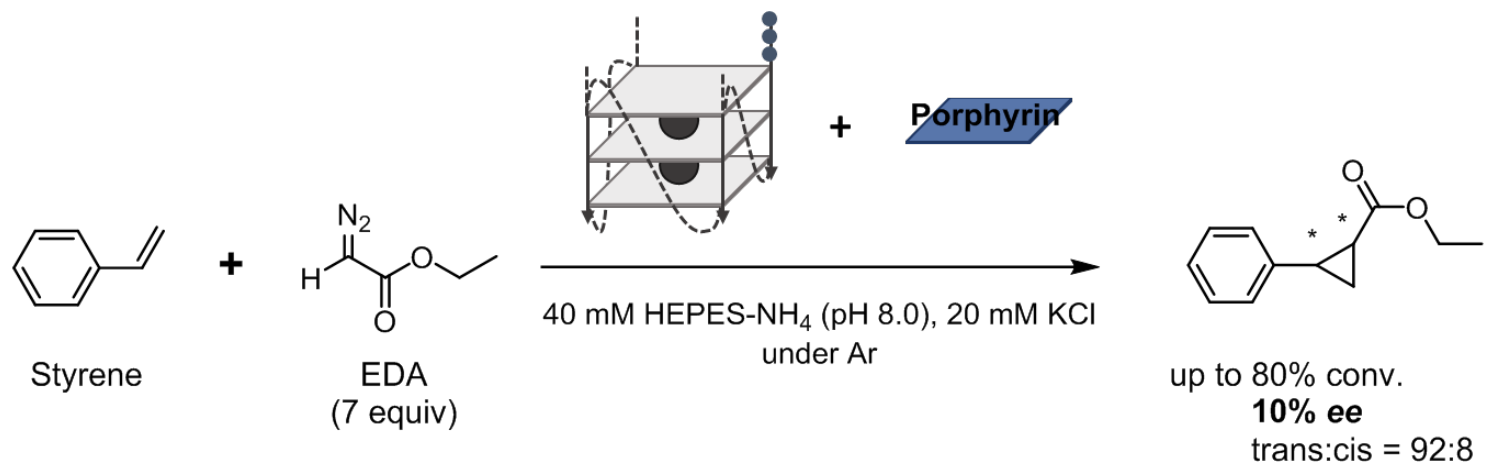

Figure 7. The first demonstration of the asymmetric synthesis of G4/Hemin DNAzyme for carbene insertion reaction (Ibrahim, ACS Omega, 2019). Copyright ACS 


\begin{tabular}{|c|c|c|c|}
\hline entry & DNAzymes and Iron porphyrin & trans : cis & yield $/ \%$ [TON] \\
\hline 1 & $\begin{array}{l}\text { No DNA } \\
\text { Fe(III)-heme }\end{array}$ & $90: 10$ & $3[1]$ \\
\hline 2 & 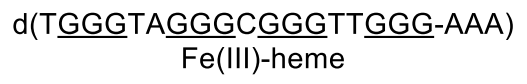 & $92: 8$ & $77[26]$ \\
\hline 3 & $d($ TGGGTAGGGCGGGTTGGG-TTT) & $92: 8$ & $80[27]$ \\
\hline 4 & $\begin{array}{c}\mathrm{d}(\mathrm{AAAA}-\mathrm{GGGGG-AAAA})_{4} \\
\mathrm{Fe}(\mathrm{III}) \text {-heme }\end{array}$ & $85: 15(10 \%$ ee $)$ & $51[17]$ \\
\hline 5 & 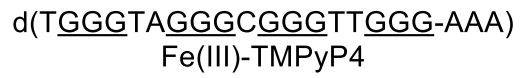 & $88: 12$ & $11[4]$ \\
\hline
\end{tabular}

Table 2. Catalytic asymmetric carbene insertion reaction catalyzed by G-quadruplex/heme DNAzymes (Ibrahim, ACS Omega, 2019). Copyright ACS.

As aforementioned, a hemin placed in the catalytic pocket of Cytochrome P450s plays a critical role in the generation and transformation of a carbene in carbenoid chemistry. ${ }^{13,20}$ Roelfes and coworkers reported a noteworthy study on carbene insertion reactions by a double-strand DNA-based hybrid catalyst. $^{21}$ Very recently, Sen and colleagues has demonstrated that heme/G-quadruplex DNAzymes catalyze carbene transfer reactions affording cyclopropane products, one of the challenging products in organic synthesis (Figure 7). ${ }^{22}$ They conducted the carbene insertion reactions between styrene and ethyl diazo acetate as the carbene donor and investigated the effect of nucleobase residues at the 3 '-end. Heme/G-quadruplex DNAzymes gave the cyclopropane product up to $80 \%$ yield (Table 2, entries 2 and 3 ), ${ }^{23}$ which is 26 -fold higher than heme-only (no DNA) reaction conditions. As shown in entry 4 in Table 2, they obtained 10\% ee with intermolecular G4 assembled heme/DNAzymes having adenine overhangs. Albeit its low stereoselectivity, this promising result suggests that complexation between structurally-tuned G-quadruplex and heme can provide chiral environment for carbene insertion reactions. Compared to heme, a cationic iron porphyrin (Fe-TMPyP4)/G4 complex gave the cyclopropane product in low yield (11\% yield, Table 2 , entry 5$)$. 


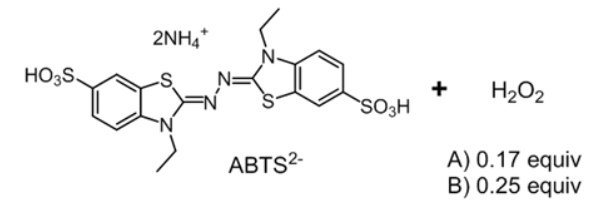

B)

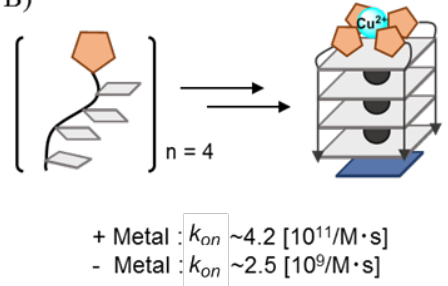

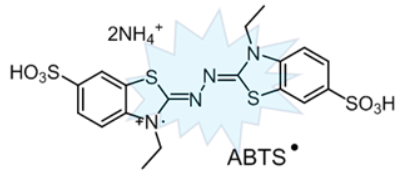
A) DNAzyme $\quad \mathrm{V}_{0}$
$\mathrm{n}=2 \quad 819[\mathrm{nM} / \mathrm{s}]$
$\mathrm{n}=3 \quad 1472[\mathrm{nM} / \mathrm{s}]$

\begin{tabular}{lc} 
B) DNAzyme & $\mathrm{V}_{0}$ \\
\hline + Metal & $785[\mathrm{nM} / \mathrm{s}]$ \\
- Metal & $281[\mathrm{nM} / \mathrm{s}]$
\end{tabular}

Figure 8. The ABTS assay for quantification of the catalytic activity of the $\mathrm{G} 4 / \mathrm{hemin}$ DNAzyme (Punt, Chem. Sci., 2019). Copyright RSC

Like the native enzyme (HRP), hemin/G-quadruplex DNAzymes promote the $\mathrm{H}_{2} \mathrm{O}_{2}$-mediated oxidation of organic substrates to afford colorimetric products such as the green color product from $2,2^{\prime}$-azino-bis(3-ethylbenzthiazoline-6-sulfonate dianion) $\left(\mathrm{ABTS}^{2-}\right)$ and initial blue to final yellow product by $3,3^{\prime}, 5,5^{\prime}$-tetramethylbenzidine (TMB), or fluorescent products such as the conversion of Amplex Red into resorufin. ${ }^{24}$ Among the various chromophore-based assays, the ABTS oxidation assay is a commonly used chromophore-based tool for quantifying catalytic performance by measurement of the corresponding radical species. The Olorunniji group compared the oxidative activity of monomer and multimer of various G-quadruplex-forming sequences based on the ABTS reaction. ${ }^{25}$ Their results clearly show a synergetic enhancement of the initial rate of reaction when the trimer quadruple-strand DNA is utilized instead of a single unit of G-quadruplex as DNAzyme, with $1472 \mathrm{nM} / \mathrm{s}$ and $639 \mathrm{nM} / \mathrm{s}$ for trimer and monomer DNAzymes, respectively (Figure 8A). Furthermore, an evaluation of the construction of the hemin/G4 DNAzyme was performed based on readout activated-ABTS by Clever and coworkers. ${ }^{26}$ They designed an intermolecular four-strand G-quadruplex connected with a metal-binding ligand, imidazole, and investigated the formation of G-quartet based on the catalytic results of the oxidation reaction. The association rate constant $\left(k_{\mathrm{on}}\right)$ indicates that coordination of the metal ions with the imidazole ligand accelerates the formation of G-quadruplex structure up to 200-fold, and the redox reaction is promoted in the presence of the $\mathrm{Cu}(\mathrm{II})$ ion, as shown in Figure 8B.

In addition, hemin/G-quadruplex DNAzymes have been used to generate chemiluminescence by the oxidation of luminol in the presence of $\mathrm{H}_{2} \mathrm{O}_{2}{ }^{24 a}$ These catalytic functions of 
hemin/G-quadruplex DNAzymes provide very useful output signals for the detection or monitoring the progress of cascade reactions as well as for the development of amplified electrochemical and optical sensors. In this context, hemin/G-quadruplex DNAzymes have been extensively applied for the development of DNA-based nanosensors, switchable DNA machines, and for the construction of DNA computing systems and logic gate circuits. ${ }^{27}$ Actually, there are many interesting applications of G-quadruplex/hemin DNAzymes and it is beyond the scope of this review to address all of them. These aspects have been described in other books as well as review articles. ${ }^{2 \mathrm{~d}, 28}$

\section{G-Quadruplex DNA-based hybrid catalysts for asymmetric reactions}

\subsection{DNA for asymmetric catalysis}


A)
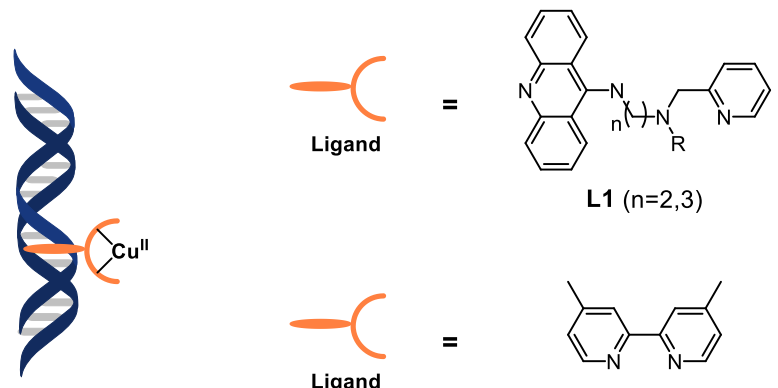

$R=$<smiles>CCCc1cc(OC)cc(OC)c1</smiles>

L1 $(n=2,3)$

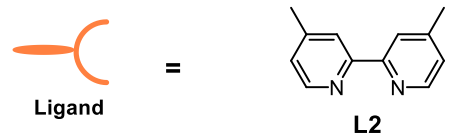

B)
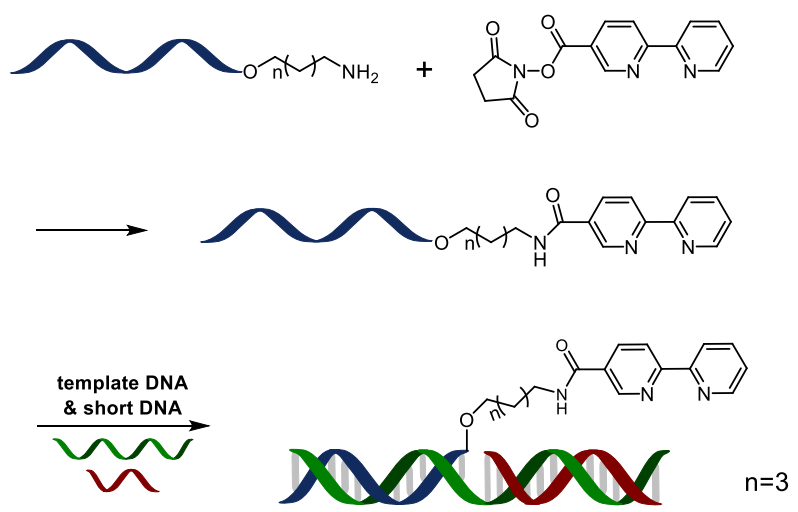

C)

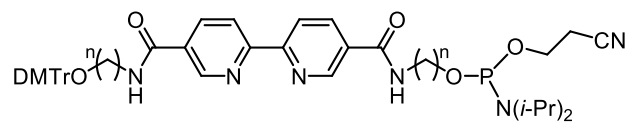

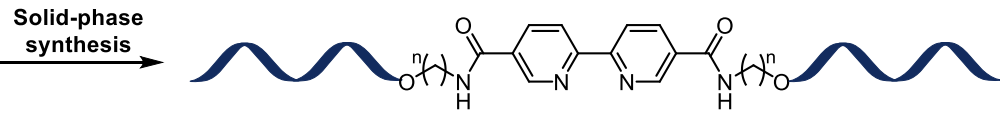

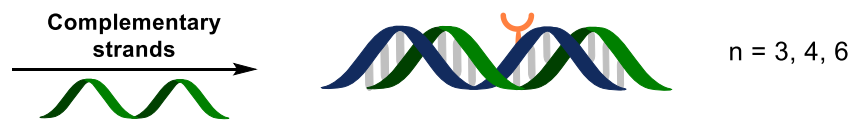

Figure 9. Canonical double-helix DNA-based hybrid catalysts

A) Supramolecular assembly strategy. B) Covalent anchoring strategy via postsynthetic modification. C) Covalent anchoring strategy via direct incorporation of binding ligand by solid-phase synthesis (Park, ACIE, 2009). Copyright WILEY-VCH

The application of double-helical DNA to asymmetric catalysis was first reported in the form 
of a copper(II)-catalyzed Diels-Alder reaction by Feringa and Roelfes in 2005. They introduced the novel concept of a catalyst, named a DNA-based hybrid catalyst, generated through the supramolecular assembly of three essential components: a catalytically active metal complex, DNA as a chiral scaffold, and a nonchiral ligand that can bind both the metal complex and the DNA. With respect to the binding ligands, the first-generation binding ligands were designed to possess two functional parts, a DNA intercalating domain (9-aminoacridine) and a metal-binding group (2-aminomethylpyridine), in one molecule, connected via a spacer linker (L1, Figure 9A). Subsequently, it was found that nearly flat, symmetrical bipyridine-type ligands such as 4,4'-dimethyl-2,2'-bipyridine (dmbpy) could be successfully applied to DNA-based asymmetric catalysis (L2, Figure 9A) ${ }^{29}$ A DNA-based hybrid catalyst consisting of $\mathrm{Cu}(\mathrm{dmbpy})$ and salmon testes DNA (st-DNA) duplex is readily generated by a straightforward supramolecular assembly strategy and has afforded high enantioselectivities in a variety of $\mathrm{Cu}(\mathrm{II})$-catalyzed asymmetric reactions such as Diels-Alder, Michael addition, and FriedelCrafts alkylations..$^{30}$

In addition, a covalent anchoring strategy has been developed in the form of postsynthetic modification of oligonucleotides or the introduction of modified nucleotides during solid-phase synthesis (Figure 9B)." Although it requires time-consuming and costly processes compared with the supramolecular assembly strategy, tunable DNA-based hybrid catalysts using the covalent anchoring strategy (Figure 9C) enable the precise positioning of the metal-ligand complex in DNA and deepens our understanding of the chiral microenvironment in DNA-based asymmetric catalysis..2 We revisit the covalent anchoring strategy later in this review.

\subsection{Supramolecular-assembled G-quadruplex DNA-based catalysts}
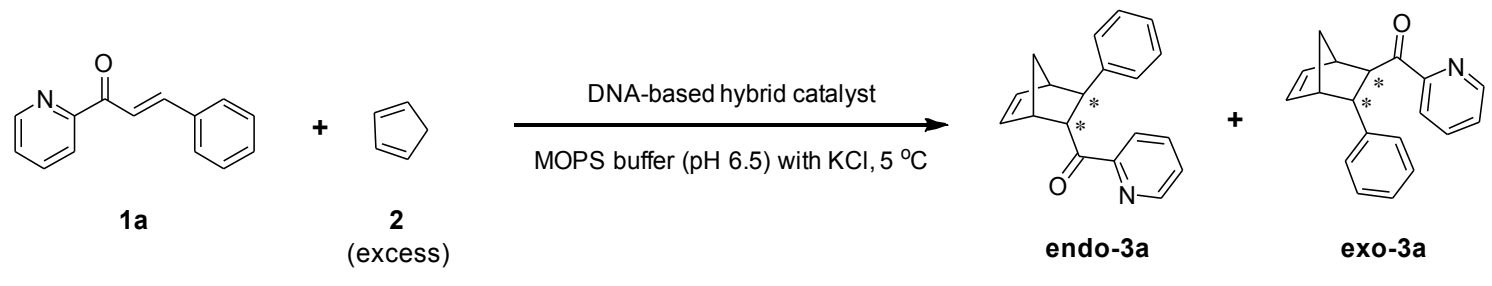

\begin{tabular}{|c|c|c|}
\hline \multirow{2}{*}{ Ligands } & \multicolumn{2}{|c|}{ G-quadruplex DNA sequence } \\
\cline { 2 - 3 } & HT21 & c-kit \\
\hline
\end{tabular}

Figure 10. Asymmetric Diels-Alder reaction catalyzed by supramolecular-assembled DNA-based hybrid catalyst and the catalytic results of the first reported G-quadruplex DNA 
catalysts comprising a $\mathrm{Cu}-\mathrm{L}$ (ee value was presented for endo isomers, which were formed as the major products with high conversions ( $>85 \%$ ) for all ligands). (Roe, Chem. Commun., 2010). Copyright RSC

The first G-quadruplex-based asymmetric catalyst was developed by Moses and coworkers in 2010. ${ }^{32}$ Two types of well-known G-quadruplex-forming sequences, HT21 and $c$-kit sequences, were utilized with the copper(II) and ligand complex to catalyze asymmetric DielsAlder reactions (Figure 10) based on the reaction conditions that have been established in duplex DNA-based asymmetric catalysis. ${ }^{11}$ In this system, HT21 with CuL2 gave the DielsAlder adduct with $-34 \% e e$, whereas $c$-kit with same CuL2 complex showed no significant enantioselectivity. Interestingly, this tendency was reversed when the CuL3 complex was employed; $c$-kit with CuL3 gave the Diels-Alder adduct with $21 \%$ ee, whereas HT21 with CuL3 complex showed no significant enantioselectivity. Although observed enantioselectivities were not practical and generally lower than duplex DNA-based asymmetric catalysis, it suggests the potential of the G-quadruplex structure as a scaffold for asymmetric catalysis. In addition, it shows that the enantiomeric preference could be changed by the combination of G-quadruplex conformation and $\mathrm{Cu}-$ ligand complex.

A)

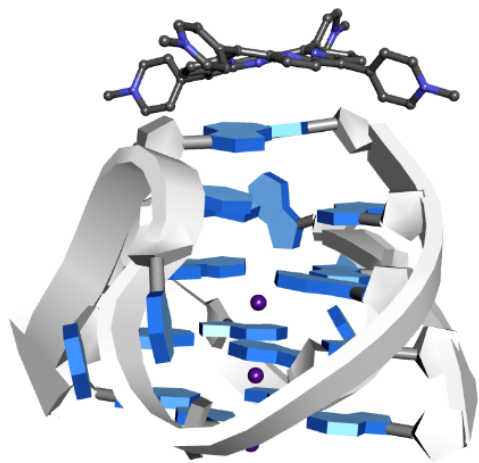

B)

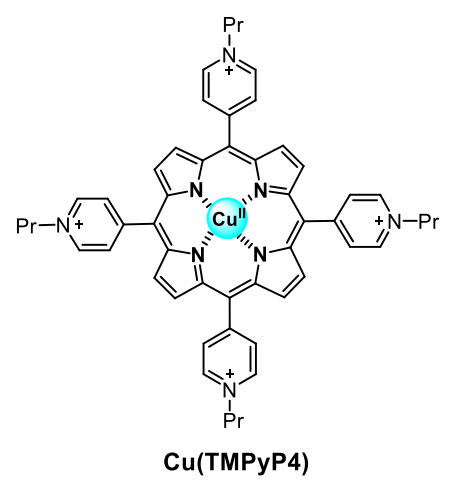

Figure 11. The structure of HT G-quadruplex DNA with porphyrin ligand (PDB ID: 2HRI) and $\mathrm{Cu}(\mathrm{II})$-coordinated TMPyP4 


\begin{tabular}{|c|c|c|c|}
\hline entry & sequences of DNA ( $\left(5^{\prime}->3^{\prime}\right)$ & endo : exo & $e^{a}[$ Conv.] $/ \%$ \\
\hline 1 & $\mathrm{~A}(\mathrm{GGGTTA})_{3} \mathrm{GGG}$ & $98: 2$ & $54[94]$ \\
\hline 2 & $\mathrm{AA}(\mathrm{GGGTTA})_{3} \mathrm{GGG}$ & $98: 2$ & $67[92]$ \\
\hline 3 & AGGGTTAGGGTTTGGGTTAGGG & $98: 2$ & 68 [92] \\
\hline 4 & $\mathrm{~A}(\mathrm{GGGTTA})_{3}$ GGGAA & $96: 4$ & $29[87]$ \\
\hline 5 & TGAGGGTGGTGAGGGTGGGGAAGG & $95: 5$ & $15[43]$ \\
\hline $6^{b}$ & $\begin{array}{l}\text { 5'-CGCTATGCTGCATCGC-3' } \\
\text { 3'-GCGATACGACGTAGCG-5' }\end{array}$ & $94: 6$ & $1[67]$ \\
\hline
\end{tabular}

Table 3. The catalytic results of the asymmetric Diels-Alder reactions catalyzed by DNA-based hybrid catalysts comprising a metalloporphyrin complex (Wilking, Org. Biol. Chem., 2013). Copyright RSC

${ }^{a}$ The ee value is presented for the endo isomers, which were formed as the major products. ${ }^{b}$ Experimental results of the canonical B-form DNA with the tetracationic $\mathrm{Cu}(\mathrm{II})$ porphyrin complex.

Metal complexes have been extensively investigated as G-quadruplex DNA binders because of their various structural and electronic properties. Metalloporphyrins received attention earlier as G-quadruplex binders because of their rigid, square-planar structures, aromatic character, and four nitrogen atoms facing the center, which can coordinate a metal ion to form a stable metal complex (Figure 11A). The binding mode of metal porphyrin complexes is considered to be a $\pi$-stacking on top of the G-tetrads at the termini of the quadruplex..$^{33}$ Based on this knowledge, an aldol reaction between a porphyrin-conjugated aldehyde and free acetone catalyzed by a proline residue containing a G-quadruplex scaffold was demonstrated. Two substrates are orientated to the active site through the binding of the metal complex and DNA and result in the formation of the corresponding product in up to $79 \%$ yield with 1800 -fold reaction rate compared with the rate with only proline catalysts. ${ }^{34}$ Furthermore, the application of metalloporphyrin to G-quadruplex DNA-based asymmetric synthesis was investigated by Hennecke and coworkers. ${ }^{7 \mathrm{a}}$ They generated a hybrid catalyst with HT21 and tetracationic $\mathrm{Cu}$ (II) porphyrin complex (Figure 11B) and examined their catalytic ability in the asymmetric DielsAlder reaction of aza-chalcone and cyclopentadiene (Figure 10). In the presence of $50 \mathrm{mM} \mathrm{KCl}$, G-quadruplex (HT21)-Cu(II) porphyrin catalyst afforded the product 3 (endo isomer) with an excellent endo selectivity (endo/exo $=98: 2$ ) and enantioselectivity of $54 \%$ ee in $94 \%$ conversion (Table 3, entry 1). 
HT21 derivatives with mutated sequences at the loop or the end of the sequence were examined as well as native HT21. For example, the addition of adenosine at the 5'-end slightly increased the enantioselectivity to $67 \%$ ee (Table 3, entry 2) compared with the native HT21-based hybrid catalyst. Similarly, perturbation of the loop by the introduction of thymidine at position 13 located the $3^{\prime}$-face as replacement of adenine also improved the enantioselectivity (68\% ee; Table 3, entry 3). However, the addition of two adenosines to the 3 '-end decreased enantioselectivity to $29 \%$ ee (Table 3, entry 4). These results indicate that the alteration of the 3 '-end influences the enantioselectivity and suggest that TMPyP4- $\mathrm{Cu}(\mathrm{II})$ might bind to the 3 '-face of the G-quadruplex. Besides HT21, the G-quadruplex-forming sequence found in the human MYC promoter region $(c-m y c)$ was also examined in this system under the optimized reaction conditions. However, use of the G-quadruplex (c-myc)-Cu(II)-TMPyP4 hybrid catalyst resulted in low enantioselectivity ( $15 \%$ ee; Table 3, entry 5). For duplex DNA, no enantioselectivity was observed (Table 3, entry 6). In this catalytic system, it is considered that aza-chalcone can coordinate to $\mathrm{Cu}(\mathrm{II})-\mathrm{TMPyP} 4$ in a monodentate axial coordination fashion given that the porphyrin coordinated $\mathrm{Cu}$ (II) ions in a tetradentate equatorial fashion.

To date, all reported examples except sulfoxidation (Figure 15) require the use of pyridyl- or imidazoyl-substituted compounds as starting materials to ensure the bidentate binding mode. G-Quadruplex-metalloporphyrin hybrid catalysts could be a solution to overcome the problem of limited substrate generality.

A)

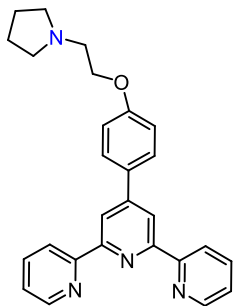

L4-a

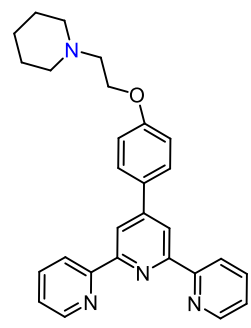

L4-b

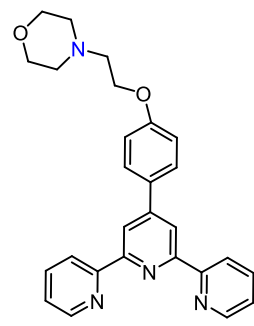

L4-c

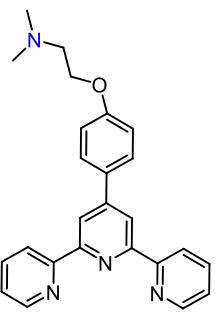

L4-d
B)

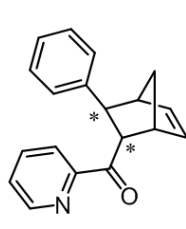

endo - $3 a$

$94 \%$ ee $99 \%$ conv.
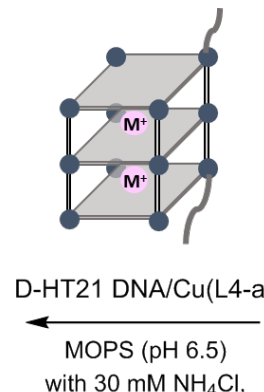

with $30 \mathrm{mM} \mathrm{NH}_{4} \mathrm{Cl}$, $5^{\circ} \mathrm{C}, 1 \mathrm{~d}$

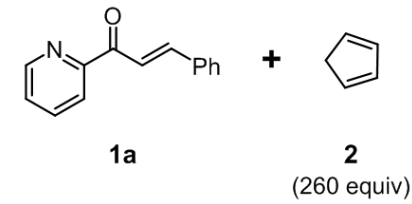

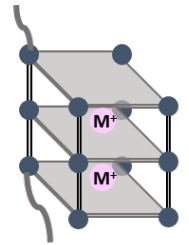

-HT21 DNA/Cu(L4-a)

MOPS (pH 6.5) with $30 \mathrm{mM} \mathrm{NH}_{4} \mathrm{Cl}$ $5^{\circ} \mathrm{C}, 1 \mathrm{~d}$

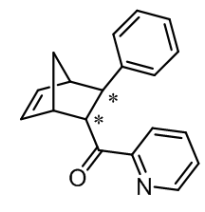

endo - 3a 
Figure 12. The opposite configuration of the enantioenriched products of the endo isomer of asymmetric Diels-Alder reactions catalyzed by D-HT21 and L-HT21 G-quadruplex DNA with $\mathrm{Cu}$ (II)-terpyridine complex. A) Aminoalkyl linker-modified terpyridine derivatives for the asymmetric Diels-Alder reaction. B) Inversion of the major enantiomer by utilizing the L-form G-quadruplex DNA with $\mathrm{Cu}(\mathrm{L} 4-\mathrm{a})$ (Li, Chem. Sci., 2015). Copyright and published by The Royal Society of Chemistry

Metal-terpyridine complexes have also been considered to be one of the efficient quadruplex binders. ${ }^{35} \mathrm{Li}$ and coworkers investigated the potential of terpyridine- $\mathrm{Cu}(\mathrm{II})$ complexes as a G-quadruplex-binding molecule for G-quadruplex DNA-based asymmetric catalysis. ${ }^{36}$ They tuned terpyridine- $\mathrm{Cu}$ (II) complexes with aminoalkyl linkers to introduce electrostatic interactions with the negative DNA backbone in the loops or grooves of the quadruplex (Figure 12A). In the presence of $\mathrm{NH}_{4}^{+}$ions, HT21-terpyridine- $\mathrm{Cu}$ (II) hybrid catalyst was utilized in asymmetric Diels-Alder reactions and afforded excellent enantioselectivity (up to 99\%) of the endo isomer and a significant rate acceleration (73-fold) compared with that of the terpyridine$\mathrm{Cu}(\mathrm{II})$ complex alone. The authors also demonstrated that the absolute configuration of the major product could be switched using a hybrid catalyst composed of terpyridine- $\mathrm{Cu}$ (II) complex and L-HT21, a mirror image of naturally occurring D-HT21 (Figure 12B).

Related to that hybrid catalyst, based on the G-quadruplex structure, Zhao and Shen reported an interesting study of the effect of various experimental parameters on catalytic results of the enantioselective Michael addition reaction. ${ }^{37}$ They investigated the influence of metal complexes, organic ionic solvent, and agitation on the catalytic outcome and concluded that a preliminary sonication of the G-quadruplex DNA with $\mathrm{Cu}(\mathrm{dmbpy})$ under aqueous conditions was most suitable for their system.

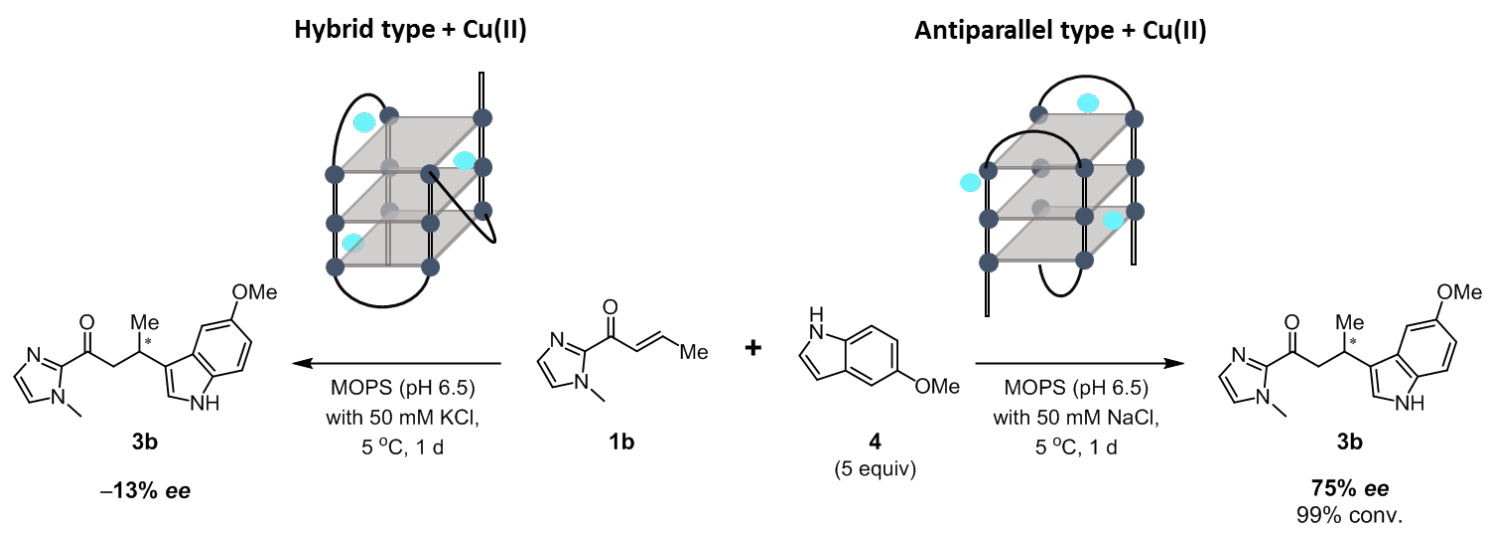


Figure 13. Enantioselective Friedel-Crafts alkylation reaction catalyzed by HT21 DNA metalloenzyme in the presence of $\mathrm{Na}^{+}$and $\mathrm{K}^{+}$ions (Wang, Chem. Commun., 2012). Copyright RSC

Interestingly, $\mathrm{Li}$ and coworkers found that G-quadruplex DNA could be applied to asymmetric reactions even if it had no binding ligand for $\mathrm{Cu}(\mathrm{II})$ ions. $^{7 \mathrm{~b}, 38}$ Enantioselective Friedel-Crafts alkylation reactions of indoles with $\alpha, \beta$-unsaturated 2-acyl imidazoles in water were explored using G-quadruplex DNA metalloenzyme generated from HT21 and $\mathrm{Cu}\left(\mathrm{NO}_{3}\right)_{2}$, and good enantioselectivity (up to $75 \%$ ee; Figure 13) was observed in the presence of $\mathrm{Na}^{+}$ ions. ${ }^{38}$ It is known that HT21 forms the antiparallel conformation in the presence of $\mathrm{Na}^{+}$ions. Addition of $\mathrm{K}^{+}$ions (hybrid-type conformation) or molecular crowding conditions with PEG200 decreased the enantioselectivity. ${ }^{9 \mathrm{~d}}$ These results suggest that the tunable conformation of the G-quadruplex significantly affects the enantioselectivity of the product of Friedel-Crafts alkylation. Given that the Friedel-Crafts reaction is one of the most powerful carbon-carbon bond-formation reactions that are available to afford indole-substituted products, which are very important building blocks in both natural products and therapeutic agents, the development of convenient and environmentally benign methods to synthesize indole derivatives has become an important research area in organic synthesis. ${ }^{39}$ With the previous report using duplex DNA-based hybrid catalyst by Boersma et al., ${ }^{30 \mathrm{a}}$ this result demonstrates that DNA-based hybrid catalysts could be an attractive alternative to develop the catalytic enantioselective Friedel-Crafts alkylation in water.

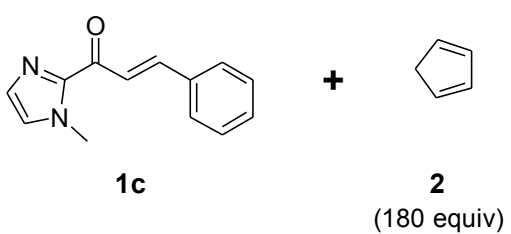

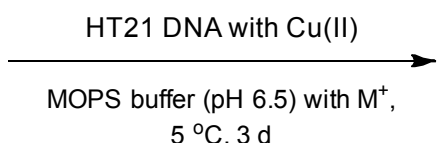

$5{ }^{\circ} \mathrm{C}, 3 \mathrm{~d}$

(180 equiv)

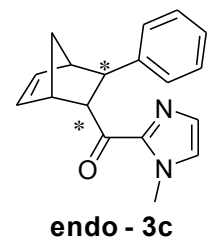

$[100 \mathrm{mM} \mathrm{NaCl}]$

$\mathbf{+ 4 9 \%}$ ee, $17 \%$ conv.

[25 $\mathrm{mM} \mathrm{KCl}]$

$-56 \%$ ee, $36 \%$ conv.

Figure 14. Asymmetric Diels-Alder reaction of $\alpha, \beta$-unsaturated 2-acylimidazoles and cyclopentadiene catalyzed by HT2 1 DNA with $\mathrm{Cu}\left(\mathrm{NO}_{3}\right)_{2}$ in the presence of different monovalent ions (Wang, ACIE, 2012). Copyright WILEY-VCH

Subsequently, the capability of G-quadruplex DNA metalloenzyme was further verified in asymmetric Diels-Alder reactions by $\mathrm{Li}$ and coworkers. ${ }^{40}$ As previously mentioned, human 
telomeric DNA sequence (HT21) tends to form an antiparallel conformation in the presence of $\mathrm{Na}^{+}$ions, whereas it forms a hybrid-type conformation in the presence of $\mathrm{K}^{+}$ions. In the DielsAlder reaction of $\alpha, \beta$-unsaturated 2-acylimidazoles and cyclopentadiene, $\mathrm{Cu}(\mathrm{II})-\mathrm{HT} 21$ metalloenzymes afforded the product endo-3c up to $49 \%$ ee in $100 \mathrm{mM} \mathrm{Na}^{+}$solution. Interestingly, the opposite enantiomer of the Diels-Alder adduct endo-3c was obtained with $56 \%$ $e e$ in the reaction catalyzed by $\mathrm{Cu}(\mathrm{II})-\mathrm{HT} 21$ metalloenzymes under $25 \mathrm{mM} \mathrm{K}^{+}$solution (Figure 14), suggesting the absolute configuration of the product in the Diels-Alder reaction could be switched depending on the structural transformation of the G-quadruplex-from an antiparallel $\left(\mathrm{Na}^{+}\right)$to a hybrid-type $\left(\mathrm{K}^{+}\right)$-by the alkali metal ion.

In general, a G-quadruplex monomer formed by short human telomeric DNA sequences (21 nt) is used as a chiral scaffold for DNA-based asymmetric catalysis. In humans, the telomere region contains approximately $200 \mathrm{nt}$ single-strand overhangs and it can form more complex G-quadruplex structures, called higher-order G-quadruplex structures, such as dimers, trimers, and multimers. ${ }^{41}$ Indeed, higher-order G-quadruplex structures are more biologically relevant than the G-quadruplex monomer. $\mathrm{Li}$ and coworkers focused on the utility of higher-order G-quadruplex structures as a chiral scaffold and exploited higher-order G-quadruplex DNA metalloenzymes in the asymmetric Diels-Alder reaction (Figure 10). ${ }^{42}$ In the presence of 150 $\mathrm{mM} \mathrm{K} \mathrm{K}^{+}$, higher-order G-quadruplex DNA (dimeric HT45 or trimeric HT69)-Cu(II) metalloenzyme catalyzed the asymmetric Diels-Alder reaction with almost full conversion and afforded the endo isomer as the major product with higher enantioselectivities (up to $92 \%$ ee) than the monomeric HT21- $\mathrm{Cu}$ (II) metalloenzyme. Higher-order G-quadruplex DNA-Cu(II) metalloenzymes also induced fivefold rate acceleration compared with the monomeric HT21 system. Through a follow-up study, Li and coworkers demonstrated that the enantioselectivity of the Diels-Alder reaction could be effectively switched with higher-order G-quadruplex DNA-Cu(II) metalloenzyme depending on the monovalent cations. HT45-Cu(II) metalloenzyme afforded the product endo-3a with $92 \%$ ee in the presence of $\mathrm{K}^{+}$ions. In contrast, $-73 \%$ ee was obtained with $\mathrm{HT} 45-\mathrm{Cu}(\mathrm{II})$ metalloenzyme in the presence of $\mathrm{NH}_{4}{ }^{+}$ions.

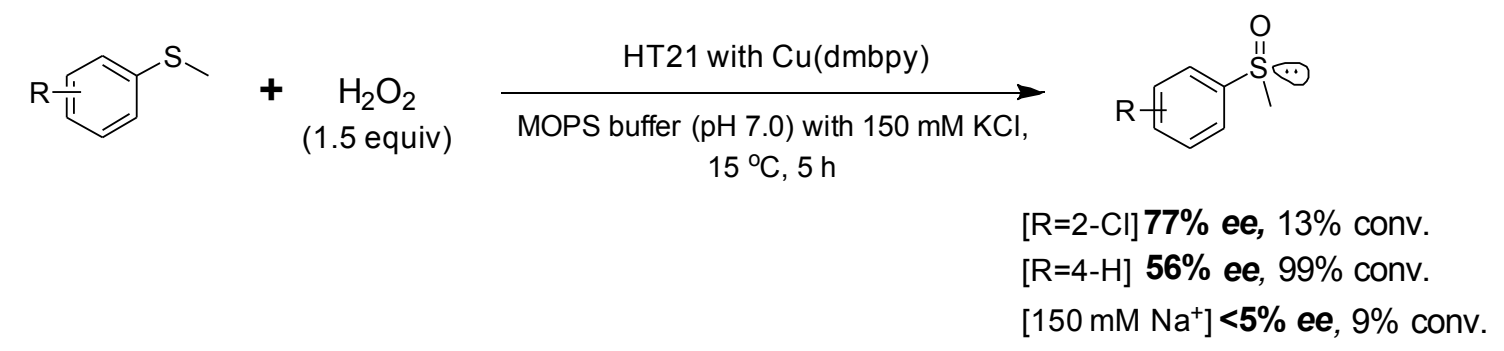

Figure 15. Asymmetric oxidation reactions of thioanisole derivatives catalyzed by HT21 
G-quadruplex DNA-based hybrid catalyst (Cheng, Chem. Commun., 2016). Copyright RSC

Besides representative carbon-carbon bond-formation reactions, the application of G-quadruplex-based hybrid catalysts has been extended to oxidation reactions. In 2016, Li and coworkers for the first time reported enantioselective sulfoxidation reactions catalyzed by supramolecular-assembled $\mathrm{Cu}(\mathrm{II}) \mathrm{L} / \mathrm{G}$-quadruplex metalloenzymes. ${ }^{43}$ The natural human telomeric sequence, 5'-(GGGTTA):GGG-3' (HT21) and modified HT21 were utilized with $\mathrm{Cu}(\mathrm{II})$-ligand complex and $\mathrm{H}_{2} \mathrm{O}_{2}$ as the oxidant. Several phenanthroline- and bipyridine-type ligands were investigated, and it was found that dmbpy was the best ligand for the sulfoxidation reaction of thioanisole derivatives. The $\mathrm{Cu}(\mathrm{II}) \mathrm{dmbpy} / \mathrm{G}$-quadruplex hybrid catalyst gave the product with full conversion and $56 \%$ ee in the presence of $\mathrm{K}^{+}$ions, whereas a racemic product with very low conversion was obtained in the presence of $\mathrm{Na}^{+}$ions (Figure 15). It is well known that HT21 forms mixed G4 structures (parallel, antiparallel, and hybrid forms) in $\mathrm{K}^{+}$solution, whereas it forms a basket antiparallel structure in $\mathrm{Na}^{+}$solution (Figure 3A). The results indicate that the catalytic ability of the $\mathrm{Cu}(\mathrm{II}) \mathrm{dmbpy} / \mathrm{G}$-quadruplex hybrid catalyst strongly depends on the G-quadruplex conformation formed in the presence of monovalent cations. This study did not provide a clear answer to the binding mode between G-quadruplex and $\mathrm{Cu}(\mathrm{II})$-dmbpy complex. It suggests that the reaction may occur both in the terminal G-tetrad and in the loop region through the investigation of the effect of flanking sequence and the loop modification. Although overall the enantioselectivities of the corresponding sulfoxides were modest, the highest enantioselectivity (up to $77 \%$ ee) was obtained with 2-chlorothioanisole, as shown in Figure 15. 


\subsection{Covalently modified G-quadruplex DNA-based catalysts}

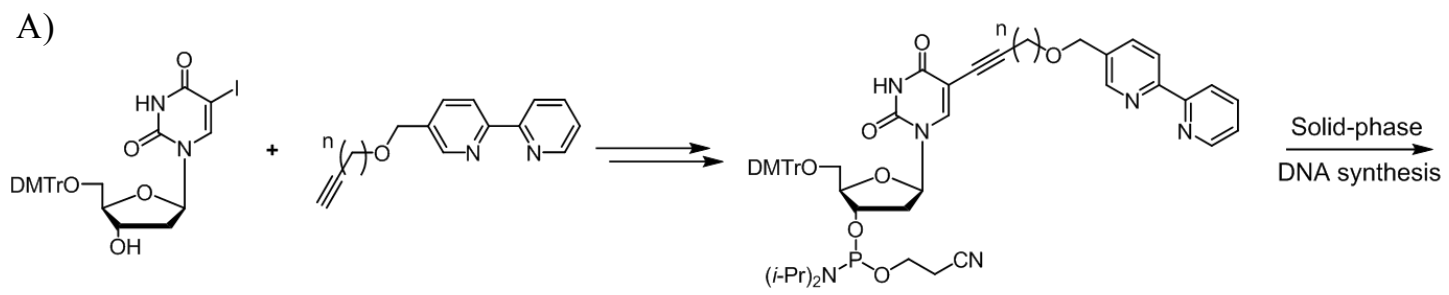

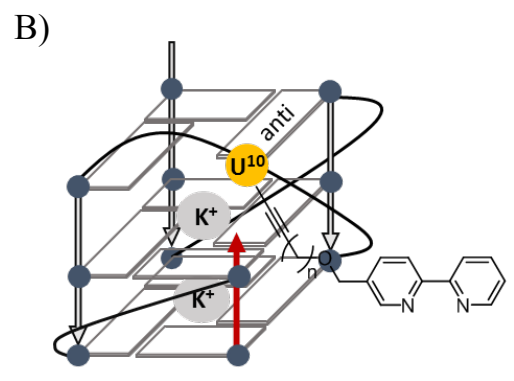

C)

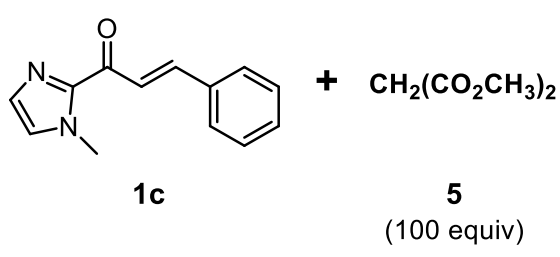

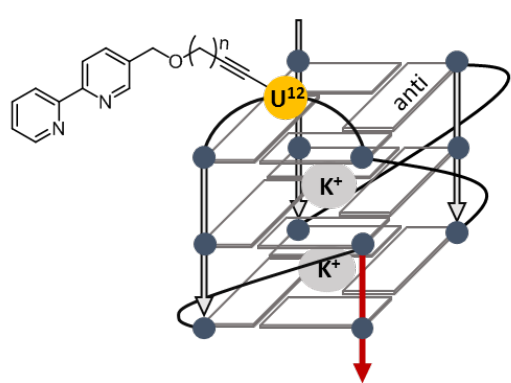

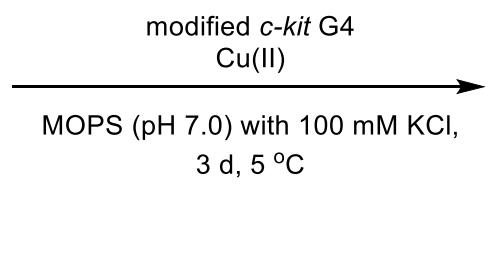

$3 d$

$\left[10^{\text {th }}\right]$ 国 $92 \%$ ee, $99 \%$ conv. $\left[12^{\text {th }}\right]+75 \%$ ee, $95 \%$ conv.

Figure 16. Fixation of the catalytic site by incorporation of the ligand covalently linked to uridine nucleotide ( $n=0-8)$ (Dey, Chem. Eur. J. 2017). Copyright Wiley-VCH

A) Synthesis of a bipyridine ligand conjugated deoxyuridine phosphoramidite unit for solid-phase DNA synthesis. B) The hypothetical hybrid-type folding of $\mathrm{dU}^{10}$-modified DNA and $\mathrm{dU}^{12}$-modified DNA. C) Asymmetric Michael addition of $\alpha, \beta$-unsaturated 2-acylimidazoles and dimethyl malonate catalyzed by $c$-kit G-quadruplex DNA-hybrid catalyst containing covalently conjugated bipyridine ligand.

The studies discussed above clearly show that supramolecular-assembled G-quadruplex DNA-hybrid catalysts with $\mathrm{Cu}(\mathrm{II})$-ligand complexes successfully work in asymmetric catalysis, and the enantioselectivity of the reactions originates from the conformation of the G-quadruplex structure. To reveal the critical factors that determine G-quadruplex DNA-based asymmetric catalysis, including the relationship between G-quadruplex topology and enantioselectivity and the binding mode of metal-ligand complexes, mechanistic investigations have been conducted 
based on fluorescence, UV-vis absorption, and CD spectroscopies. ${ }^{44}$ Despite these efforts, supramolecular-assembled G-quadruplex-based hybrid catalysts have not provided a straight answer to which active site in the DNA quadruplex structure controls catalytic performance because it is difficult to control the location of the metal-ligand complex in the DNA. Although the monomeric G-quadruplex structure formed by the human telomeric DNA sequence has been well characterized by X-ray crystallography and NMR-based studies, ${ }^{9}$ there is no X-ray crystal structure of a G-quadruplex DNA-hybrid catalyst formed by G-quadruplex DNA and $\mathrm{Cu}$ (II)-binding ligand complex. For the precise positioning of the metal-ligand complex in DNA (as shown in Figure 9B, 9C), covalent anchoring strategies have been developed for the introduction of modified nucleotides during solid-phase synthesis. ${ }^{32}$ The covalent anchoring strategy is one of the major solutions that enables the precise positioning of the metal-ligand complex in DNA and it provides important information on the DNA microenvironment that

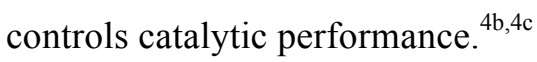

Jäschke and coworkers devised modified G-quadruplex-based hybrid catalysts with a covalently linked bipyridine ligand and investigated asymmetric Michael addition reactions of $\alpha, \beta$-unsaturated 2-acylimidazoles and dimethyl malonate. ${ }^{45}$ The authors chose the $c$-kit sequence (5'-AGGGAGGGCGCTGGGAGGAGGG-3') to design the G-quadruplex-based hybrid catalysts. The unique parallel G-quadruplex structure of the $c$-kit has been well studied by X-ray crystallography and NMR spectroscopy. ${ }^{46}$-Iodo-deoxyuridine was chosen as a building block to functionalize a bipyridine ligand through Sonogashira coupling (Figure 16A). As shown in Figure 16B, the authors picked positions 10 and 12 for ligand attachment and incorporated a deoxyuridine derivative covalently modified at the C5-position with bipyridine ligand via alkyne linkers of different lengths through solid-phase synthesis.

The $c$-kit quadruplexes modified with alkynyl-bipyridine ligand were successfully applied to asymmetric Michael addition reactions and provided useful information with which to tune the enantioselectivity in quadruplex-based asymmetric catalysis such as the conformation of the G-quadruplex, position of ligand, and the length of the linker. The length of the linker used to connect the deoxyuridine base and bipyridine ligand affects the catalysis differently, coupled with the position of bipyridine on the G-quadruplex structure. Interestingly, their study demonstrated that the stereochemical outcome could be easily inverted by adjusting the position of the bipyridine ligand; $\mathrm{Cu}(\mathrm{II})$-bipyridine-tethered G-quadruplex DNA modified at position 10 afforded the (-)-enantiomer with up to $92 \%$ ee, whereas the $\mathrm{Cu}(\mathrm{II})$-bipyridine-tethered G-quadruplex DNA modified at position 12 afforded the (+)-enantiomer with up to $75 \%$ ee (Figure 16C). 
A)

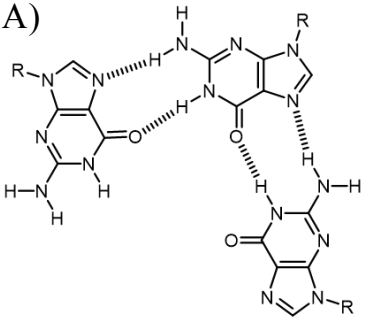

$\equiv$

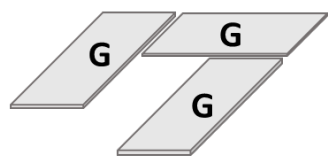

G-triad

B)
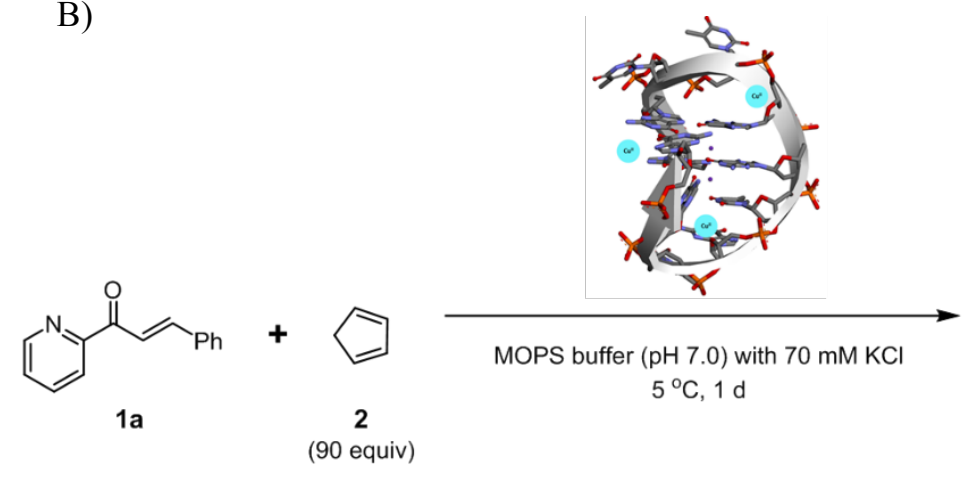

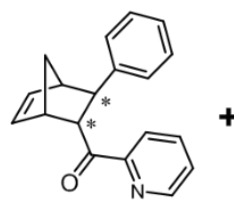

endo isomer up to $64 \%$ ee $99 \%$ conv.

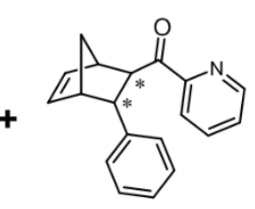

exo isomer

Figure 17. G-triad and G-triplex metalloenzymes (Xu, Catal. Commun., 2016) Copyright and published by Elsevier

A) Guanine triad plane formed by Hoogsteen base pairing. B) Asymmetric reaction catalyzed by the G-triplex structure as a noncanonical DNA scaffold (PDB ID: 2MKM)

It is known that a G-rich sequence with three G-tracts can form a G-triplex structure with stacked G-triad layers, in which a central guanine interacts with two other guanines by Hoogsteen-like hydrogen bonds (Figure 17A). ${ }^{47}$ Recently, Limongelli and coworkers proved the formation of G-triplex with the G-rich sequence, 5'-GGTTGGTGTGG-3', based on NMR studies. $^{48}$ Zhou and coworkers utilized the G-triplex structure formed with 5'-GGTTGGTGTGG-3' as a chiral scaffold in the $\mathrm{Cu}(\mathrm{II})$-catalyzed asymmetric Diels-Alder reaction. ${ }^{49}$ In the presence of $70 \mathrm{mM} \mathrm{K}^{+}$, G-triplex DNA-Cu(II) metalloenzyme catalyzed the asymmetric Diels-Alder reaction with full conversion and provided the endo isomer as the major product with up to 64\% ee (Figure 17B). Albeit with moderate enantioselectivities, this study suggests that the G-triplex structure could also be used as a chiral scaffold for DNA-based asymmetric catalysis.

\section{Conclusion and Perspectives}

G-Quadruplexes are versatile scaffolds for catalysis. They provide an apoenzyme 
environment that can bind cofactors such as hemin and $\mathrm{Cu}(\mathrm{TMPyP} 4)$. The peroxidase-mimicking activity of hemin/G-quadruplex DNAzymes has been extensively studied and used in a broad range of applications. However, despite the usefulness of hemin/G-quadruplex DNAzymes, its low catalytic efficiency compared with protein enzymes is an important issue that needs to be improved. For native heme enzymes, the amino acid residue is considered to be a crucial factor that contributes to the outstanding catalytic efficiency of enzymes. In general, many peroxidase enzymes use the imidazole moiety of a histidine residue as the axial ligand for ferric ion at the fifth coordination position. ${ }^{50}$ In the case of DNAzymes, although the binding mode of the cofactor and the DNA remains unclear, the nucleobase group could act as a ligand and be involved in the catalytic competency of the hemin/G-quadruplex DNAzymes. Very recently, an in-depth study on the enhancement of proximal nucleobases for the catalytic efficiency of hemin/G-quadruplex DNAzymes has been reported. ${ }^{51}$ The information on the synergistic performance of the G-quartet core and the nucleotides proximal to the hemin-binding site has expanded our understanding of the hemin/G-quadruplex DNAzymes and facilitated the rational design of G-quadruplex-based catalysts. Moreover, the effort to broaden application examples of the hemin/G-quadruplex catalyst by expanding the substrate scope is necessary. Klibanov and colleagues investigated substrate selectivity in peroxidation reactions of various phenolic substrates including tyrosine and its derivatives with heme, heme/DNAzyme and horseradish peroxidase (HRP). ${ }^{.8}$ In the case of the tyrosine, the DNAzyme were remarkably more active and showed a high enhancement of the reaction rate in comparison to hemin only, 88-fold for D-tyrosine and 68-fold for L-tyrosine respectively. In addition, relative rate of the DNAzyme to HRP are 18-fold for D-tyrosine and 27-fold for L-tyrosine respectively, suggesting aptamer-induced rate acceleration.

For G-quadruplex-based hybrid catalysts in asymmetric catalysis, there are several challenges before these catalysts match the real needs of synthetic chemistry. Most of the applications described in this review rely on the representative carbon-carbon bond-formation reactions such as Diels-Alder reaction, Michael addition, and Friedel-Crafts reactions. These Lewis acidic $\mathrm{Cu}$ (II)-catalyzed reactions have already been extensively investigated by duplex DNA-based hybrid catalysts and it was found that their substrates are limited to chalcone derivatives with pyridyl- or imidazoyl-substituents for the bidentate coordination to metal ions. Likewise, this narrow substrate scope is an important issue to overcome. Recently, Abe and coworkers developed polyethylene glycol (PEG)-modified DNA and verified the G-quadruplex structure in organic solvents such as methanol, acetonitrile, and 1,4-dioxane.s. The authors also demonstrated that PEG-DNA/hemin complexes could exhibit peroxidase activity in organic media. This result suggests that we could develop DNA-hybrid catalytic systems for organic media, and this would lead to widespread applications. Despite the remaining challenges, DNA 
is a cost-effective, chemically, and thermally stable biomolecule compared with proteins. The systematic and controllable structural diversity of the G-quadruplex make the application of noncanonical DNA structures particularly attractive. We believe that there is an unexplored potential of this peculiar structure such as the development of new metalloenzymes based on the interaction between G-quadruplex (or triplex) and metal ions. We hope that this review inspires the interest of many scientists in this young interdisciplinary research area.

\section{Conflicts of interest}

There are no conflicts to declare.

\section{Acknowledgements}

We express sincere thanks for a Grant-in-Aid Priority Research (16H06356 for H. S) from Japan Society for the Promotion of Science (JSPS). We also thank KAKENHI program (Grant-in-Aid for scientific research C, 18K05315) for support to S. P.

\section{References}

1. (a) R. D. Fleischmann, M. D. Adams, O. White, R. A. Clayton, E. F. Kirkness, A. R. Kerlavage, C. J. Bult, J. F. Tomb, B. A. Dougherty, J. M. Merrick, Science 1995, 269, 496-512.; (b) J. C. Venter, M. D. Adams, E.W. Myers, P. W. Li, R. J. Mural, G. G. Sutton, H. O. Smith, M. Yandell C. A. Evans, R. A. Holt, J. D. Gocayne, Science 2001, 291, 1304-1351.; (c) E. Andrianantoandro, S. Basu, D. K. Karig, R. Weiss, Mol. Syst. Biol. 2006, 2, 2006.2008.; (d) E. T. Cirulli, D. B. Goldstein, Nat. Rev. Genet. 2010, 11, 415.

2. (a) N. C. Seeman, Nature 2003, 421, 427.; (b) P. W. Rothemund, Nature 2006, 440, 297.; (c) J. Bath, A. J. Turberfield, Nat. nanotech. 2007, 2, 275.; (d) J.-L. Mergny, D. Sen, Chem. Rev. 2019, 119, 6290-6325.

3. (a) S. K. Silverman, Angew. Chem., Int. Ed. 2010, 49, 7180-7201.; (b) L. C. H. Poon, S. P. Methot, W. Morabi-Pazooki, F. Pio, A. J. Bennet, D. Sen, J. Am. Chem. Soc. 2011, 133, 18771884.

4. (a) G. Roelfes, B. L. Feringa, Angew. Chem. Int. Ed. 2005, 44, 3230-3232.; (b) S. Park, H. Sugiyama Angew. Chem. Int. Ed. 2010, 49, 3870-3878.; (c) S. Park, H. Sugiyama Molecules 2012, 17, 12792-12803.; (d) A. Rioz-Martínez, G. Roelfes, Curr. Opin. Chem. Biol. 2015, 25, 80-87; (e) N. Duchemin, I. Heath-Apostolopoulos, M. Smietana, S. Arseniyadis Org. Biomol. Chem. 2017, 15, 7072-7087.

5. (a) G. Gupta, M. Bansal, V. Sasisekharan, Proc. Natl. Acad. Sci. U. S. A. 1980, 77, 64866490.; (b) R. D. Wells, D. A. Collier, J. C. Hanvey, M. Shimizu, F. Wohlrab, FASEB J. 1988, 2 , 2939-2949.; (c) A. T. Phan, V. Kuryavyi, D. J. Patel, Curr. Opin. Struct. Biol. 2006, 16, $288-$ 
298.; (d) J. Choi, T. Majima, Chem. Soc. Rev. 2011, 40, 5893-5909.

6. (a) S. Burge, G. N. Parkinson, P. Hazel, A. K. Todd, S. Neidle, S. Nucleic Acids Res. 2006, 34, 5402-5415.; (b) A. T. Phan, V. Kuryavyi, K. Luu, D. J. Patel, Quadruplex Nucleic Acids 2006, 81-99.; (c) J. L. Huppert, FEBS J. 2010, 277, 3452-3458.

7. (a) M. Wilking, U. Hennecke, Org. Biomol. Chem. 2013, 11, 6940-6945.; (b) C. Wang, G. Jia, Y. Li, S. Zhang, C. Li, Chem. Commun. 2013, 49, 11161-11163.; (c) L. X., Wang, J. F. Xiang, Y. L. Tang, Adv. Synth. Catal. 2015, 357,13

8. (a) M. Gellert, M. N. Lipsett, D. R. Davies, Proc. Natl. Acad. Sci. U. S. A. 1962, 48, $2013-$ 2018.; (b) D. Sen, W. Gilbert, Nature 1988, 334, 364-366.; (c) J. R. Williamson, M. Raghuraman, T. R. Cech, Cell 1989, 59, 871-880.

9. (a) Y. Wang, D. J. Patel, Structure 1993, 1, 263-282.; (b) G. N. Parkinson, M. P. Lee, S. Neidle, Nature 2002, 417, 876-880.; (c) K. N. Luu, A. T. Phan, V. Kuryavyi, L. Lacroix, D. J. Patel, J. Am. Chem. Soc. 2006, 128, 9963-9970.; (d) A. Ambrus, D. Chen, J. Dai, T. Bialis, R. A. Jones, D. Yang, Nucleic Acids Res. 2006, 34, 2723-2735.

10. A. I. Karsisiotis, N. M. Hessari, E. Novellino, G. P. Spada, A. Randazzo, M. W. da Silva, Angew. Chem. Int. Ed. 2011, 123, 10833-10836.

11. N. Smargiasso, F. Rosu, W. Hsia, P. Colson, E. S. Baker, M. T. Bowers, E. De Pauw, V. Gabelica, J. Am. Chem. Soc. 2008, 130, 10208-10216.

12. (a) T. G. Traylor, Acc. Chem. Res. 1981, 14, 102-109.; (b) P. R. Ortiz de Montellano, Annu. Rev. Pharmaco. 1992, 32, 89-107.

13. H. Renata, Z. J. Wang, F. H. Arnold, Angew. Chem. Int. Ed 2015, 54, 3351-3367.

14. (a) Y. Li, D. Sen, Nat. Struct. Biol. 1996, 3, 743-747.; (b) S. L. Rebelo, M. Linhares, M. M. Simões, A. M. Silva, M. G. P. Neves, J. A. Cavaleiro, C. Freire, J. Catal. 2014, 315, 33-40.; (c) K. Rybicka-Jasińska, W. Shan, K. Zawada, K. M. Kadish, D. Gryko, J. Am. Chem. Soc. 2016, $138,15451-15458$.

15. P. Travascio, Y. Li, D. Sen, Chem. Biol. 1998, 5, 505-517.

16. L. C. Poon, S. P. Methot, W. Morabi-Pazooki, F. Pio, A. J. Bennet, D. Sen, J. Am. Chem. Soc. 2011, 133, 1877-1884.

17. E. Golub, R. Freeman, I. Willner, Angew. Chem. Int. Ed. 2011, 50, 11710-11714.

18. A. M. Rojas, P. A. Gonzalez, E. Antipov, A. M. Klibanov, Biotechnol. Lett. 2007, 29, $227-$ 232.

19. (a) E. Golub, R. Freeman, I. Willner, Anal. Chem. 2013, 85, 12126-12133.; (b) E. Golub, H. B. Albada, W. Liao, Y. Biniuri, I. Willner, J. Am. Chem. Soc. 2015, 138, 164-172.; (c) H. B. Albada, E. Golub, I. Willner, Chem. Sci. 2016, 7, 3092-3101.; (d) Y. Biniuri, B. Albada, M. Wolff, E. Golub, D. Gelman, I. Willner, ACS Catal. 2018, 8, 1802-1809.

20. (a) Y. Li, J. S. Huang, Z. Y. Zhou, C. M. Che, X. Z. You, J. Am. Chem. Soc. 2002, 124, 
13185-13193.; (b) Y. Wei, A. Tinoco, V. Steck, R. Fasan, Y. Zhang, J. Am. Chem. Soc. 2017, 140, 1649-1662.

21. A. Rioz-Martínez, J. Oelerich, N. Ségaud, G. Roelfes, Angew. Chem., Int. Ed. 2016, 55, 4136-14140

22. H. Ibrahim, P. Mulyk, D. Sen, ACS Omega 2019, 12, 15280-15288.

23. P. Travascio, D. Sen, A. J. Bennet, Can. J. Chem. 2006, 84, 613-619.

24. (a) Y. Xiao, V. Pavlov, R. Gill, T. Bourenko, I. Willner, ChemBioChem 2004, 5, 374-379.;

(b) S. Nakayama, H. O. Sintim, Mol. BioSyst. 2009, 6, 95-97.; (c) P. D. Josephy, T. Eling, R. P. Mason, J. Biol. Chem. 1982, 257, 3669-3675.

25. R. I. Adeoye, D. S. Osalaye, T. K. Ralebitso-Senior, A. Boddis, A. J. Reid, A. A. Fatokun, A. K. Powell, S. O. Malomo, F. J. Olorunniji, Catal. 2019, 9, 613.

26. P. M. Punt, H. Clever, Chem. Sci. 2019, 10, 2513-2518.

27. (a) Y. Weizmann, M. K. Beissenhirtz, Z. Cheglakov, R. Nowarski, M. Kotler, I. Willner, Angew. Chem. Int. Ed. 2006, 45, 7384-7388.; (b) M. Luo, X. Chen, G. Zhou, X. Xiang, L. Chen, X. Ji, Z. He, Chem. Commun. 2012, 48, 1126-1128.; (c) Y. Yuan, G. Liu, R. Yuan, Y. Chai, X. Gan, L. Bai, Biosens. Bioelectron. 2013, 42, 474-480.; (d) H. Jiang, Z. Liang, Y. Ma, D. Kong, Z. Hong, Anal. Chem. Acta 2016, 943, 114-122.

28. (a) J. Kosman, B. Juskowiak, Anal. Chem. Acta 2011, 707, 7-17.; (b) Y. Gao, L. Liu, N. Xia, Aust. J. Biosens. Bioelectron. 2015, 1, 1009.; (c) N. Shumayrikh, D. Sen, in in G-Quadruplex Nucleic Acids, ed. nonymous Springer, 2019, 357-368.

29. (a) G. Roelfes, A. J. Boersma, B. L. Feringa, Chem. Commun. 2006, 635-637.; (b) A. J. Boersma, B. L. Feringa, G. Roelfes, Org. Lett. 2007, 9, 3647-3650.

30. (a) A. J. Boersma, B. L. Feringa, G. Roelfes, Angew. Chem. Int. Ed. 2009, 121, 3396-3398.; (b) S. Park, K. Ikehata, R. Watabe, Y. Hidaka, A. Rajendran, H. Sugiyama, Chem. Commun. 2012, 48, 10398-10400.; (c) G. P. Petrova, Z. Ke, S. Park, H. Sugiyama, K. Morokuma, Chem. Phys. Lett. 2014, 600, 87-95.

31. N. S. Oltra, G. Roelfes, Chem. Commun. 2008, 6039-6041.

32. (a) S. Park, L. Zheng, S. Kumakiri, S. Sakashita, H. Otomo, K. Ikehata, H. Sugiyama, ACS Catal. 2014, 4, 4070-4073.; (b) S. Park, I. Okamura, S. Sakashita, J. H. Yum, C. Acharya, L. Gao, H. Sugiyama, ACS Catal. 2015, 5, 4708-4712.; (c) J. H. Yum, S. Park, R. Hiraga, I. Okamura, S. Notsu, H. Sugiyama, Org. Biomol. Chem. 2019, 17, 2548-2553.; (d) J. Mansot, S. Aubert, N. Duchemin, J. J. Vasseur, S. Arseniyadis, M. Smietana, Chem. Sci. 2019, 10, 2875-2881.

32. S. Roe, D. J. Ritson, T. Garner, M. Searle, J. E. Moses, Chem. Commun. 2010, 46, 43094311.

33. (a) F. X. Han, R. T. Wheelhouse, L. H. Hurley, J. Am. Chem. Soc. 1999, 121, 3561-3570.; 
(b) H. Han, D. R. Langley, A. Rangan, L. H. Hurley, J. Am. Chem. Soc. 2001, 123, 8902-8913.;

(c) S. Asamitsu, T. Bando, H. Sugiyama, Chem. Eur. J. 2018, 25, 417-430.

34. Z. Tang, D. P. Gonçalves, M. Wieland, A. Marx, J. S. Hartig, ChemBioChem, 2008, 9, 1061-1064.

35. (a) H. Bertrand, D. Monchaud, A. De Cian, R. Guillot, J. Mergny, M. Teulade-Fichou, Org. Biomol. Chem. 2007, 5, 2555-2559.; (b) S. N. Georgiades, N. Abd Karim, K. Suntharalingam, R. Vilar, Angew. Chem. Int. Ed. 2010, 49, 4020-4034.

36. Y. Li, M. Cheng, J. Hao, C. Wang, G. Jia, C. Li, Chem. Sci. 2015, 6, 5578-5585.

37. H. Zhao, K. Shen, Biotechnol. Prog. 2016, 32, 891-898.

38. C. Wang, Y. Li, G. Jia, Y. Liu, S. Lu, C. Li, C. Chem. Commun. 2012, 48, 6232-6234.

39. T. B. Poulsen, K. A. Jørgensen, Chem. Rev. 2008, 108, 2903-2915.

40. C. Wang, G. Jia, J. Zhou, Y. Li, Y. Liu, S. Lu, C. Li, Angew. Chem. Int. Ed. 2012, 51, $9352-$ 9355.

41. (a) E. H. Blackburn, Cell 2001, 106, 661-673.; (b) H. Yu, D. Miyoshi, N. Sugimoto, J. Am. Chem. Soc. 2006, 128, 15461-15468.

42 (a) Y. Li, G. Jia, C. Wang, M. Cheng, C. Li, ChemBioChem 2015, 16, 618-624.; (b) Y. Li, C. Wang, J. Hao, M. Cheng, G. Jia, C. Li, Chem. Commun. 2015, 51, 13174-13177.

43. M. Cheng, Y. Li, J. Zhou, G. Jia, S. Lu, Y. Yang, C. Li, Chem. Commun. 2016, 52, 96449647.

44. M. Cheng, J. Hao, Y. Li, Y. Cheng, G. Jia, J. Zhou, C. Li, Biochimie 2018, 146, 20-27.

45. (a) S. Dey, A. Jäschke, Angew. Chem. Int. Ed. 2015, 54, 11279-11282.; (b) S. Dey, C. L. Rühl, A. Jäschke, Chem. Eur. J. 2017, 23, 12162-12170.

46. (a) S. Rankin, A. P. Reszka, J. Huppert, M. Zloh, G. N. Parkinson, A. K. Todd, S. Ladame, S. Balasubramanian, S. Neidle, J. Am. Chem. Soc. 2005, 127, 10584-10589.; (b) A. T. Phan, V. Kuryavyi, S. Burge, S. Neidle, D. J. Patel, J. Am. Chem. Soc. 2007, 129, 4386-4392. 47. M. D. Frank-Kamenetskii, S. M. Mirkin, Annu. Rev. Biochem. 1995, 64, 65-95. 48. V. Limongelli, S. De Tito, L. Cerofolini, M. Fragai, B. Pagano, R. Trotta, S. Cosconati, L. Marinelli, E. Novellino, I. Bertini, Angew. Chem. Int. Ed. 2013, 125, 2325-2329.

49. X. Xu, W. Mao, F. Lin, J. Hu, Z. He, X. Weng, C. Wang, X. Zhou, Catal. Commun. 2016, 74, 16-18.

50. (a) T. L. Poulos, J. Kraut, J. Biol. Chem. 1980, 255, 8199-8205.; (b) J. H. Dawson, Science 1988, 240, 433-439.

51. J. Chen, Y. Zhang, M. Cheng, Y. Guo, J. S poner, D. Monchaud, J. L. Mergny, H. Ju, J. Zhou, ACS Catal. 2018, 8, 11352-11361.

52. H. Abe, N. Abe, A. Shibata, K. Ito, Y. Tanaka, M. Ito, H. Saneyoshi, S. Shuto, Y. Ito, Angew. Chem. Int. Ed. 2012, 124, 6581-6585. 
